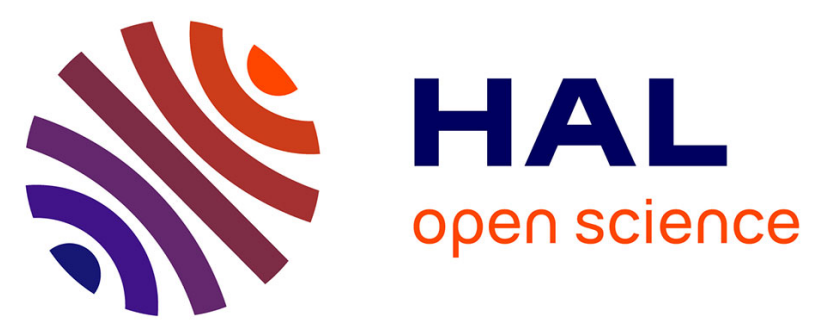

\title{
Nouvelles données géologiques et téphrochronologiques sur le gisement paléontologique du maar de Senèze (Pléistocène inférieur, massif central, France)
}

Jean-François Pastre, Evelyne Debard, Sébastien Nomade, Hervé Guillou, Martine Faure, Claude Guérin, Eric Delson

\section{To cite this version:}

Jean-François Pastre, Evelyne Debard, Sébastien Nomade, Hervé Guillou, Martine Faure, et al.. Nouvelles données géologiques et téphrochronologiques sur le gisement paléontologique du maar de Senèze (Pléistocène inférieur, massif central, France). Quaternaire, 2015, 26 (3), pp.225-244. 10.4000/quaternaire.7368 . hal-02334190

\section{HAL Id: hal-02334190 https://univ-lyon1.hal.science/hal-02334190}

Submitted on 12 Oct 2020

HAL is a multi-disciplinary open access archive for the deposit and dissemination of scientific research documents, whether they are published or not. The documents may come from teaching and research institutions in France or abroad, or from public or private research centers.
L'archive ouverte pluridisciplinaire HAL, est destinée au dépôt et à la diffusion de documents scientifiques de niveau recherche, publiés ou non, émanant des établissements d'enseignement et de recherche français ou étrangers, des laboratoires publics ou privés. 


\section{Quaternaire}

Revue de l'Association française pour l'étude du

Quaternaire

vol. 26/3 | 2015

Volume 26 Numéro 3

Nouvelles données géologiques et téphrochronologiques sur le gisement paléontologique du maar de Senèze (Pléistocène inférieur, massif central, France)

New geological and tephrochronological data on the palaeontological site of the Senèze maar (early Pleistocene, massif central, France)

Jean-François Pastre, Evelyne Debard, Sébastien Nomade, Hervé Guillou, Martine Faure, Claude Guérin et Eric Delson

\section{OpenEdition}

Journals

Édition électronique

URL : http://journals.openedition.org/quaternaire/7368

DOI : 10.4000 /quaternaire.7368

ISSN : 1965-0795

Éditeur

Association française pour l'étude du quaternaire

Édition imprimée

Date de publication : 1 septembre 2015

Pagination : 225-244

ISSN : 1142-2904

Référence électronique

Jean-François Pastre, Evelyne Debard, Sébastien Nomade, Hervé Guillou, Martine Faure, Claude Guérin et Eric Delson, « Nouvelles données géologiques et téphrochronologiques sur le gisement paléontologique du maar de Senèze (Pléistocène inférieur, massif central, France) », Quaternaire [En ligne], vol. 26/3 | 2015, mis en ligne le 01 septembre 2017, consulté le 20 décembre 2019. URL : http:// journals.openedition.org/quaternaire/7368 ; DOI : 10.4000/quaternaire.7368 


\title{
NOUVELLES DONNÉES GÉOLOGIQUES ET TÉPHROCHRONOLOGIQUES SUR LE GISEMENT PALÉONTOLOGIQUE DU MAAR DE SENÈZE (PLÉISTOCÈNE INFÉRIEUR, MASSIF CENTRAL, FRANCE)
}

\author{
Jean-François PASTRE ${ }^{1}$, Évelyne DEBARD ${ }^{2}$, Sébastien NOMADE ${ }^{3}$, \\ Hervé GUILLOU ${ }^{3}$, Martine FAURE $^{4}$, Claude GUÉRIN ${ }^{5}$ \& Eric DELSON ${ }^{6}$
}

\begin{abstract}
RÉSUMÉ
Le système volcanique de Senèze (Domeyrat, Haute-Loire) comprend une coulée de basanite, des scories, un cratère de maar et des produits phréatomagmatiques. De nouvelles recherches de terrain et une cartographie détaillée précisent leur géométrie et leurs relations géologiques. Le maar recèle un important gisement fossilifère du Pléistocène inférieur qui a livré quarante espèces de mammifères attribuées à la biozone MNQ 18, pour laquelle le maar de Senèze est la localité de référence. Les fouilles réalisées entre 2001 et 2006 ont permis de collecter de nouveaux spécimens et de préciser leur contexte stratigraphique et géodynamique. Le gisement se situe sur les rivages du paléolac et enregistre différents épisodes lacustres et d'apports de versant liés à la variabilité climatique contemporaine. Les dépôts qui en résultent renferment plusieurs loci fossilifères d'âges proches. La découverte de dix téphras émis par le strato-volcan du Mont-Dore, situé $60 \mathrm{~km}$ au NO, fournit un cadre téphrochronologique remarquable. Comptetenu de l'altération systématique des verres, leur composition est déterminée par leur contenu minéralogique (feldspaths, amphiboles brunes, diopsides brun et vert, titanite, apatite, zircon, biotite-phlogopite, oxydes de Fe-Ti) et la composition chimique des feldspaths (anorthose, sanidine sodique et plagioclases). L'étude de ces téphras montre l'importance de l'activité pyroclastique contemporaine à dominance trachytique et confirme le polyphasage de la mise en place du gisement. Les datations ${ }^{40} \mathrm{Ar} /{ }^{39} \mathrm{Ar}$ laser sur feldspaths alcalins de cinq téphras montrent toutefois une fourchette de datation relativement étroite comprise entre 2,09 et 2,21 $\pm 0,02 \mathrm{Ma}(1 \sigma$, âge relatif à ACs-2 à 1,201 Ma). Senèze s'affirme ainsi comme un gisement clé du Pléistocène inférieur en Europe.
\end{abstract}

Mots-clés : Pléistocène inférieur, gisement paléontologique, téphras, datations ${ }^{40} \mathrm{Ar} /{ }^{39} \mathrm{Ar}$ laser, Massif central, France

\section{ABSTRACT}

NEW GEOLOGICAL AND TEPHROCHRONOLOGICAL DATA ON THE PALAEONTOLOGICAL SITE OF THE SENÈZE MAAR (EARLY PLEISTOCENE, MASSIF CENTRAL, FRANCE)

The volcanic system of Senèze (Domeyrat, Haute-Loire) comprises a basanite flow, scoriae, a maar crater and phreatomagmatic products. New field research and detailed cartography clarify their geometry and geological relationships. The maar contains an important palaeontological site of the Early Pleistocene that yielded forty species of mammals attributed to the biozone MNQ 18 (of which it is the reference locality). The excavations undertaken between 2001 and 2006 recovered new fossils and documented their stratigraphic and geodynamic context. The fossiliferous site is located on the shore of the palaeolake and includes several lacustrine and slope deposits linked to the contemporaneous climatic changes which in turn produced a number of locally fossiliferous findspots which appear to be close in age. The discovery of ten tephras emitted by the Mont-Dore strato-volcano, situated $60 \mathrm{~km}$ to the NW allowed development of a remarkable tephrochronological framework. Because of the intense weathering of the tephras, their composition is determined by their mineralogical content (feldspars, brown amphiboles, brown and green diopside, titanite, apatite, zircon, biotite-phlogopite, Fe-Ti oxides) and the chemical composition of feldspars (anorthoclase, sodic sanidine and plagioclases). The study of these tephras reveals the importance of the contemporaneous (mainly trachytic) pyroclastic activity and confirms the polyphased deposition of the site. The ${ }^{40} \mathrm{Ar} /{ }^{39} \mathrm{Ar}$ laser dating of alkali feldspars from five tephras shows a relatively narrow range of age comprised between 2.09 and $2.21 \pm 0.02 \mathrm{Ma}(1 \sigma$, age relative to ACs-2 standard at $1.201 \mathrm{Ma})$. Senèze is thus confirmed as a key Early Pleistocene palaeontological site in Europe.

Keywords : Early Pleistocene, palaeontological site, tephras, ${ }^{40} \mathrm{Ar} /{ }^{39} \mathrm{Ar}$ laser datings, Massif Central, France

\footnotetext{
${ }^{1}$ Laboratoire de Géographie Physique. Environnements quaternaires et actuels, UMR 8591 CNRS \& Universités Paris 1 et Paris 12, 1 place Aristide Briand, FR-92195 MEUDON cedex.Courriel: pastre@cnrs-bellevue.fr

${ }^{2}$ Laboratoire de Géologie, UMR 5276, Université Lyon 1, bâtiment Géode, 2 rue Raphaël Dubois, FR-69622 VILLEURBANNE cedex.

Courriel: evelyne.debard@univ-lyon1.fr

${ }^{3}$ Laboratoire des Sciences du Climat et de l'Environnement, avenue de la Terrasse, FR-91198 GIF-SUR-YVETTE cedex.

Courriels: Sebastien.Nomade@1sce.ipsl.fr, Herve.Guillou@1sce.ipsl.fr

${ }^{4}$ Université Lumière Lyon 2, UFR Temps et Territoires, 5 avenue Pierre Mendès-France, FR-69676 BRON cedex.

Courriel: martine.faure@mom.fr

${ }_{5}^{5}$ Laboratoire de Géologie de Lyon, UMR 5276, LGLTPE, Université Claude Bernard - Lyon 1, 27-43 boulevard du 11 Novembre 1918, FR-69622 VILLEURBANNE cedex. Courriel: claude.guerin@univ-lyon1.fr

${ }^{6}$ Department of Anthropology, Lehman College, City University of New York et Department of Vertebrate Paleontology, American Museum of Natural History, NEW YORK, NY 10024, USA. Courriel: Eric.Delson@lehman.cuny.edu
} 


\section{1 - INTRODUCTION}

Le volcanisme alcalin du Massif central français est caractérisé par une activité majeure au cours du Pléistocène inférieur (Maury \& Varet, 1980; Brousse \& Lefèvre, 1990, Nehlig et al., 2003). Cette activité concerne deux provinces volcaniques: le Devès, basaltique et le MontDore, strato-volcan différencié qui est la source de nombreux téphras (Pastre \& Cantagrel, 2001 ; Nomade $e t$ al., 2014b) (fig. 1). Elle est accompagnée par la mise en place de séquences volcano-sédimentaires importantes comme dans le bassin du Puy (Bout, 1960; Defive et al., 2005) ou la vallée de l'Allier (Bout, 1960; Pastre, 1987, 2004b).

Le maar de Senèze (Domeyrat, Haute-Loire, fig. 1) constitue un site clef au sein de cet ensemble de sites fréquemment fossilifères. Il comporte en effet un gisement de vertébrés exceptionnel (Delson et al., 2006) et une séquence lacustre dilatée de grand intérêt palynologique et paléoclimatique (Elhaï, 1969; Ablin, 1991). S'inscrivant dans l'activité basaltique du nord du Devès, il a également enregistré différentes éruptions pyroclastiques du Mont-Dore qui se retrouvent sous forme de niveaux de téphras intercalés au sein du gisement fossilifère. Cet article se propose de s'intéresser au contexte géologique et volcanologique du volcan de Senèze, à l'étude géologique des formations du gisement fossilifère et à l'étude des téphras et leur datation par la méthode ${ }^{40} \mathrm{Ar} /{ }^{39} \mathrm{Ar}$ sur monocristal au laser.

\section{2 - CONTEXTE GÉOLOGIQUE ET VOLCANOLOGIQUE DU MAAR DE SENÈZE}

\section{1 - DONNÉES GÉNÉRALES}

Le contexte géologique et volcanologique du système volcanique de Senèze a été étudié par Grangeon (1962), Devis (1969, 1970), Bout (1970, 1978) et Lasnier et al. (1982). Ces auteurs proposent diverses interprétations qui seront précisées ici grâce à de nouvelles observations de terrain et à une nouvelle cartographie du secteur.

Comme différents cratères phréatomagmatiques, le maar de Senèze ne constitue pas un appareil strictement monogénique. Il est associé à des émissions de scories et une coulée basanitique, la coulée des Laniers (ou de Senèze). Il est aussi bordé par un croissant de tufs phréatomagmatiques contemporain de sa formation (fig. 2 et 3).

Dans toutes les études antérieures, la coulée des Laniers est considérée marquer le début de l'activité.

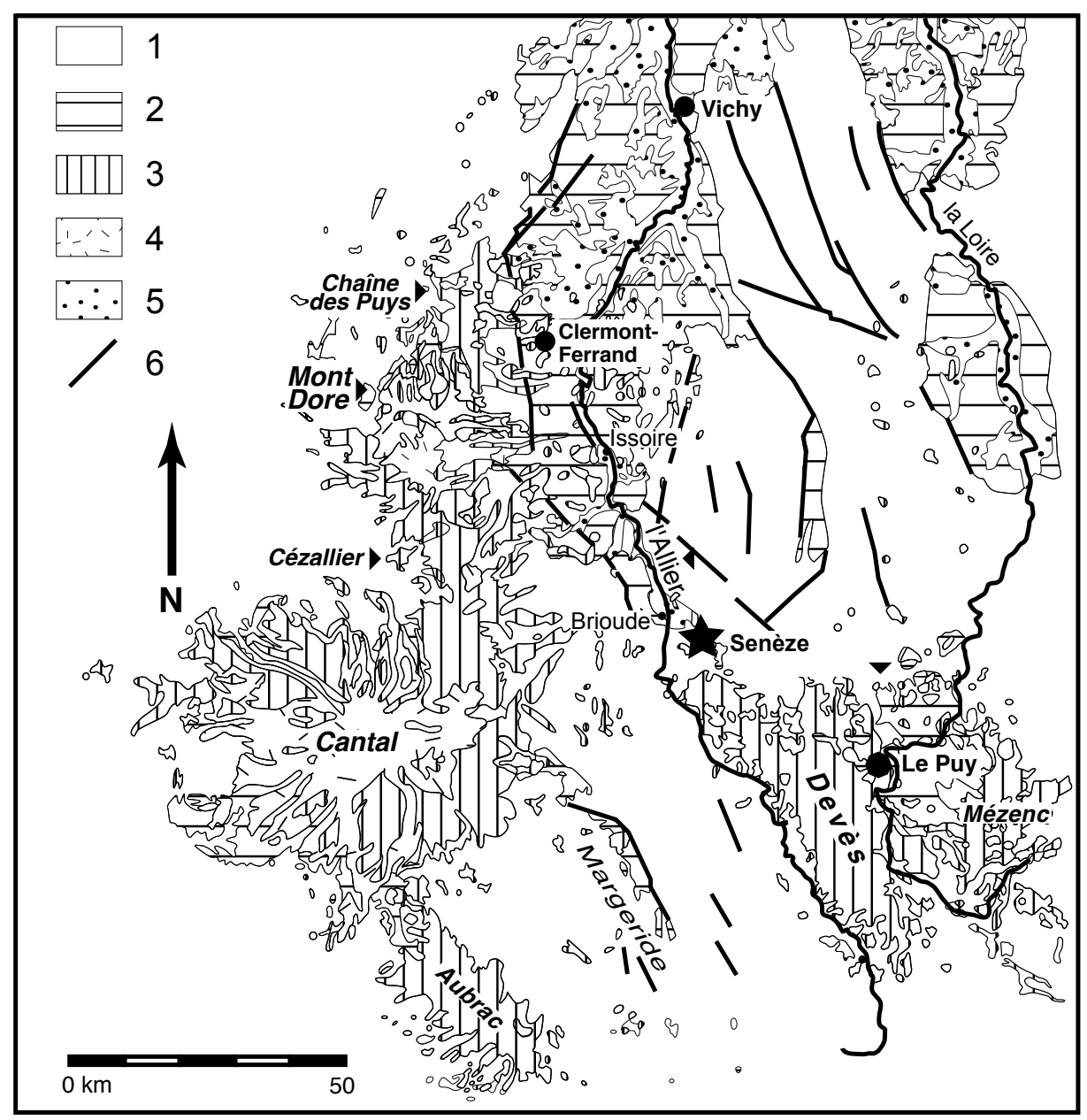

Fig. 1 : Carte géologique simplifiée du volcanisme du Massif central et localisation du site de Senèze.

1/ Socle hercynien, 2/ Sédiments tertiaires, 3/Volcanisme cénozoïque effusif, 4/ Pyroclastites et épiclastites, 5/ Sédiments quaternaires, 6/ Failles. Fig. 1: Simplified geological map of the Massif Central volcanism and location of the Senèze site. 1/ Hercynian basement, 2/Tertiary sediments, 3/ Cenozoïc volcanism (lava flows), 4/ Pyroclastites and epiclastites, 5/ Quaternary sediments, 6/ Faults. 


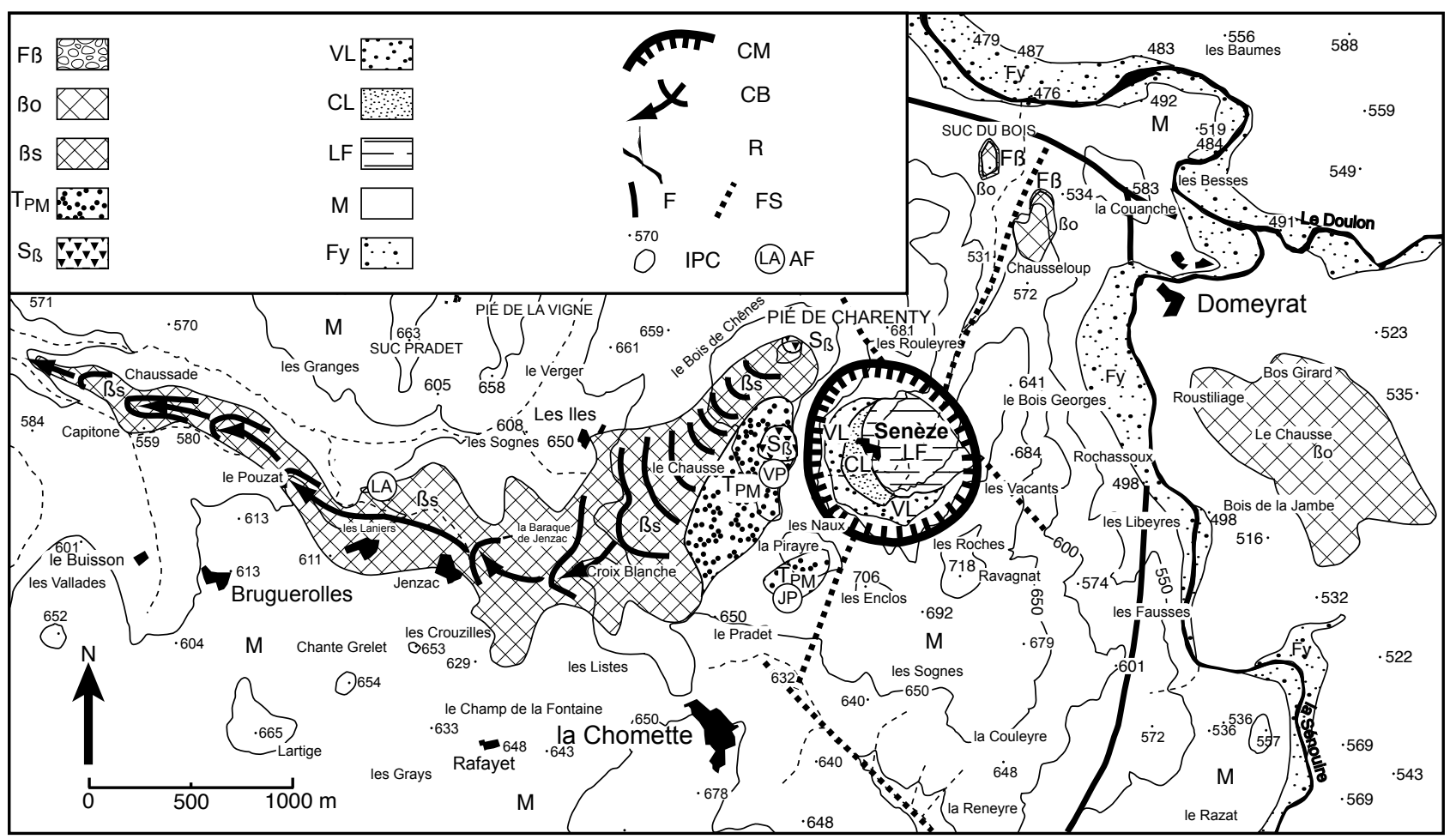

Fig. 2 : Carte géologique du secteur de Senèze.

Fß/ Alluvions sous-basaltiques, ß0/ Basaltes de la Sénouire, ßs/ Basanite de Senèze-Les Laniers, TPM/ Tufs et brêches phréatomagmatiques, Sß/ Scories basaltiques, VL/ Dépôts de pente et faciès lacustres externes, CL/ Colluvions et faciès lacustres de transition, LF/ Faciès lacustres internes (argiles, silts et sables), M/ Socle métamorphique (gneiss), Fy/ Alluvions récentes, CM/ Cratère de maar, CB/ Coulée basanitique et sens d'écoulement, R/ Rivière, F/ Faille, Faille supposée, IPC/ Isohypses équidistance $50 \mathrm{~m}$ et points-côtés NGF, AF/ Affleurements: LA: Les Laniers RN 102, JP: carrière de la Jeune Pireyre, VP: carrière de la Vieille Pireyre.

Fig. 2: Geological map of Senèze area. Fß/ Subasaltic alluvium, $\beta 0 /$ Sénouire basalts, $\beta$ s/ Senèze-Les Laniers basanite, TPM/Phreatomagmatic tuffs and brecciae, S $3 /$ Basaltic scoriae, VL/ Slope deposits and external lacustrine facies, CL/Colluvium and lacustrine transitional facies, LF/ Internal lacustrine facies (clays, silts and sands), M/ Metamorphic basement (gneiss), Fy/ Recent alluvium, CM/ Maar crater, CB/ Basanite flow and flowing direction, R/ Rivers, F/ Fault, FS/ Supposed fault, IPC/ Altimetric curves $50 \mathrm{~m}$ distant and NGF altimetric points, AF/ Outcrops: LA: Les Laniers RN 102, JP: la Jeune Pireyre quarry, VP: la Vieille Pireyre quarry.

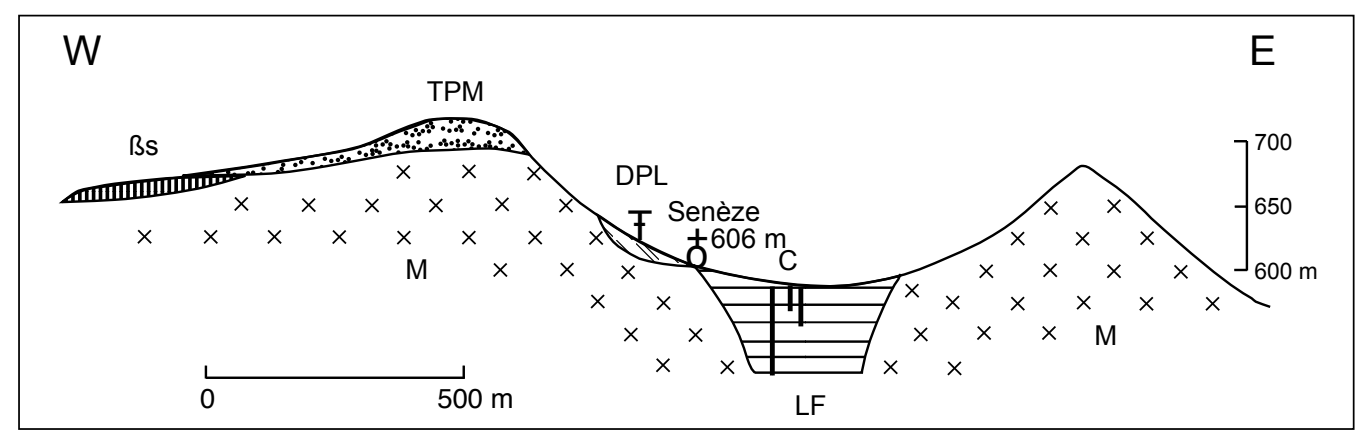

Fig. 3 : Coupe est-ouest du maar de Senèze.

ßs/ Basanite de Senèze-Les Laniers, TPM/ Tufs et brêches phréatomagmatiques, DPL/ Dépôts de pente et hauts niveaux lacustres fossilifères, C/ Carottages, LF/ Faciès lacustres internes (argiles, silts et sables), M/ Socle (gneiss ultramétamorphiques).

Fig. 3: East-west cross-section of the Senèze maar. $\beta$ s/Senèze-Les Laniers basanite, TPM/Phreatomagmatic tuffs and brecciae, DPL/Slope and upper lacustrine fossiliferous deposits, C/ corings, LF/ Internal lacustrine facies (clays, silts and sands), M/ Basement (ultrametamorphic gneiss).

Cette position est déduite du fait qu'elle domine le maar sans l'avoir oblitéré. Les vues diffèrent par contre sur la position des scories et des produits de maar, les cartes et les données de terrain des différents auteurs donnant plusieurs interprétations des formations volcaniques et de leur extension.

\section{2 - LA COULÉE DES LANIERS ET LES FORMATIONS CONTEMPORAINES}

La coulée de basanite des Laniers (ou coulée de Senèze) se situe à l'ouest du cratère de maar (fig. 2 et 3 ). Cette coulée a recouvert une topographie déprimée irrégulière. Son origine est clairement située au "Pié de Charenty», mais cette butte ne correspond pas au cône de scories décrit par la plupart des auteurs et cartographié en scories stromboliennes sur la carte géologique de Brioude au $1 / 50000^{\mathrm{e}}$ (Lasnier et al., 1982). Il s'agit d'une intrusion massive de basanite continuant directement la coulée.

La plupart des limites entre la coulée et le socle sont masquées et seuls quelques affleurements exposent le contact. Une coupe complète peut être observée le long de la nationale 102, près du hameau des Laniers, exposant: 
1- le socle métamorphique (gneiss), visible sur $6 \mathrm{~m}$;

2- des colluvions plus ou moins riche en quartz incluant une proportion importante d'éléments de socle: $100 \mathrm{~cm}$ environ;

3a- un tuf argileux avec des grains de basalte fortement altérés et de rares fragments de socle: $55 \mathrm{~cm}$;

3b- un tuf argileux ocre-brun avec nombreux petits grains de basalte $<1 \mathrm{~cm}: 30 \mathrm{~cm}$;

4- une coulée de basanite: larges prismes altérés; la texture de la base des prismes est vitreuse: $280 \mathrm{~cm}$.

L'antériorité de la coulée des Laniers par rapport au maar est probable. En effet, si elle avait été postérieure elle aurait coulé dans le maar et l'aurait oblitéré. Les tufs qui précèdent la coulée prouvent l'existence d'une activité volcanique antérieure. La rareté et la distance des autres appareils du secteur s'accordent mal avec la présence de ces tufs qui résultent donc de la phase d'activité initiale du système. L'hypothèse d'une courte activité phréatomagmatique avant la mise en place de la coulée semble donc l'hypothèse la plus raisonnable actuellement.

Cette coulée est datée par K/Ar à 2,28 $\pm 0,15$ et 2,30 \pm $0,15 \mathrm{Ma}$ (Prévot \& Dalrymple, 1970) et 2,52 $\pm 0,06 \mathrm{Ma}$ (Couthures \& Pastre, 1983). L'écart entre ces datations nécessiterait de nouvelles mesures pour pouvoir trancher sur l'âge réel de cette coulée.

\section{3 - LES SCORIES}

Concernant les scories, la carte géologique au $1 / 50000^{\mathrm{e}}$ de Brioude (Lasnier et al., 1982) est erronée. Il est attribué une importance excessive aux scories situées à l'ouest du maar et figuré comme scories une partie des tufs phréatomagmatiques du maar.

Le Pié de Charenty est interprété par la plupart des auteurs comme un cône de scories correspondant exactement à la butte du même nom. Cette interprétation due à la morphologie convexe de la butte doit être rejetée. Les flancs sud-est et sud-ouest de la butte montrent de la basanite, alors que le versant nord est modelé dans le socle métamorphique (fig. 2). Seules quelques scories soudées exposées au nord du sommet coté $754 \mathrm{~m}$ indiquent une petite activité de fontaine de lave.

Le seul affleurement significatif de scories de Senèze est de relativement petite taille. Il affleure au sud du Pié de Charenty et est clairement distinct de la basanite formant la butte. Composé de scories rouges, il borde le cratère d'explosion $450 \mathrm{~m}$ à l'ouest du hameau de Senèze et est directement bordé par les tufs de maar au sud et au nord (fig. 2). Ces scories sont remaniées dans les dépôts de pente intracratériques (ex. tranchées T1 et $\mathrm{T} 2$ des fouilles du gisement fossilifère). Dans la première des hypothèses, ces scories précèdent les tufs phréatomagmatiques. Ces tufs qui ne recouvrent pas les scories sont érodés. La solution d'un cône de scories recoupé par le maar concorde avec cette hypothèse. Dans la seconde hypothèse, beaucoup moins probable, ces scories pourraient suivre les tufs, expliquant leur disparition et le contact rapide entre eux.
Actuellement cette question ne peut être tranchée définitivement, mais l'hypothèse d'un cône de scories contemporain de la coulée et partiellement détruit par le maar plus jeune semble raisonnable. Nous n'avons jamais observé les relations stratigraphiques entre les deux formations. D'après Couthures et al. (1991) une coupe montrerait les scories recouvrant les tufs phréatomagmatiques. Cependant, nous n'avons jamais observé une telle coupe, donc les scories pourraient être de nature colluviale.

\section{4 - LES TUFS PHRÉATOMAGMATIQUES}

Les tufs phréatomagmatiques forment un croissant bordant les limites ouest et sud-ouest du cratère de maar. Sur la carte de la figure 2 son extension est largement différente de celle figurée sur la carte géologique de Brioude au $1 / 50000^{\circ}$ où elle est limitée à un petit affleurement au sud du système à proximité de la départementale D20. Il recouvre deux affleurements : (1) à $750 \mathrm{~m}$ au nord-est de la Chomette, au sud de la butte $722 \mathrm{~m}$, (2) entre la base nord de la butte 697 (S) et le thalweg localisé au sud de la butte $717 \mathrm{~m}$ du Pié de Charenty (N). La partie centrale de ce dernier affleurement est interrompue par les scories précédemment exposées. Ces affleurements ont été exploités en carrières à la «Vieille Pireyre» au nord et à la «Jeune Pireyre» au sud (cf. localisation des affleurements sur la figure 2).

Dans la carrière de la «Vieille Pireyre» environ $5 \mathrm{~m}$ de tufs phréatomagmatiques sont visibles. La section type est la suivante:

1- tuf cendreux induré avec une matrice cendreuse brune englobant des feldspaths, du quartz, des amphiboles et de la biotite $<1 \mathrm{~mm}$, petits lapilli de basanite disséminés dans la matrice: $1 \mathrm{~m}$ visible;

2- tuf à blocs et lapilli avec lits granoclassés (épaisseur des lits $<20 \mathrm{~cm}$ ), matrice cendreuse moins abondante, nombreux fragments lithiques: basanite juvénile vitreuse (= plus de $70 \%$ ), gneiss $(<30 \%)$, blocs de socle $<20 \mathrm{~cm}$, un gros bloc d'environ $1 \mathrm{~m}^{3}$, quelques amphiboles brunes : épaisseur $2 \mathrm{~m}$;

3- tuf cendreux induré, homogène, non lité, à granulométrie fine, pauvre en lithiques: épaisseur environ $2 \mathrm{~m}$.

La succession observée dans la carrière de la «Jeune Pireyre» est différente. La section type visible dans la partie est de la carrière est la suivante:

1- tufs phréatomagmatiques composés de cinq sousunités:

a- tuf induré avec environ $90 \%$ de lapilli de basanite $<$ $2 \mathrm{~cm}$ et environ $10 \%$ de gneiss non lité, visible sur une épaisseur de 2,50 m;

b- cendre brune soudée: $0,10 \mathrm{~m}$;

c- tuf à lapilli similaire à a) : $1,5 \mathrm{~m}$ environ;

$\mathrm{d}$ - tuf fin brun très pauvre en fragments lithiques: $1 \mathrm{~m}$ environ;

e- tuf lité granoclassé (dans la partie centrale de la carrière) : $1,5 \mathrm{~m}$ environ;

2- tuf lité granoclassé (lits de $<1 \mathrm{~cm}$ à $5 \mathrm{~cm}$ ) texture sableuse à sablo-graveleuse : $0,9 \mathrm{~m}$; 
3- tuf massif soudé et non lité à texture sableuse, rares fragments lithiques: environ $2 \mathrm{~m}$.

Ces formations sont caractérisées par leur richesse en lapilli et en blocs et leur faciès induré qui correspond probablement à une induration primaire. L'absence de litage dans plusieurs couches évoque un faciès d'écoulement différent des classiques faciès de déferlantes basales litées qui sont trouvés couramment dans la plupart des maars. Ces spécificités posent la question de la genèse de ces produits phréatomagmatiques. L'induration pose la question d'une origine thermique ou hydromagmatique. Le faciès d'écoulement peut être autant phréatomagmatique qu'épiclastique. La richesse en blocs indique une forte activité explosive. La fréquence de mégacristaux d'amphiboles (xénolithes d'origine profonde) est à signaler. La composition minéralogique met en évidence la présence de minéraux de lherzolites: olivine, enstatite et diopside chromifère associés à des minéraux volcaniques: olivine et clinopyroxène brun et à des minéraux du socle: quartz, feldspaths, biotite, grenats et sillimanite.

Ces formations ont été canalisées sur une paléomorphologie contrastée. La position subverticale du tuf de la «Jeune Pireyre» par rapport au socle évoque un probable paléoversant d'une petite paléovallée. Comme le tuf de la «Jeune Pireyre» atteint environ $50 \mathrm{~m}$ d'épaisseur de $670 \mathrm{~m}$ à $722 \mathrm{~m}$, une telle épaisseur résulte donc probablement d'un contrôle topographique.

D'autres tufs phréatomagmatiques peuvent être observés dans une position interne dans la partie sud du cratère. Représentés par des tufs soudés sans litage, ils sont très riches en xénolithes de socle $<2 \mathrm{~cm}$ avec de rares bombes de basanite indurée. Ces tufs peuvent avoir été plaqués dans le cratère lors de la phase éruptive ou correspondre à un effondrement de l'anneau de tuf lié à un mouvement de masse. Des effondrements plus limités de tufs phréatomagmatiques se sont produits pendant la mise en place des dépôts fossilifères comme cela est visible par exemple dans la coupe A (cf. partie 3.3.1.1) où un gros bloc de tuf peut être observé au sein des dépôts.

\section{3 - LE CONTEXTE PALÉOENVIRONNEMENTAL ET GÉODYNAMIQUE DU GISEMENT FOSSILIFÈRE}

\section{1 - DONNÉES GÉNÉRALES}

La coupe de la figure 3 permet de reconnaître l'organisation des formations affleurant au niveau du maar de Senèze. La partie inférieure du cratère de maar est occupée par des formations lacustres surmontant le diatrème. Le carottage réalisé en 1965 a traversé 123 m de sédiments représentés par des niveaux à dominante sableuse (80 à $123 \mathrm{~m}$.) surmontés par des argiles diatomifères (Elhaï, 1969). Onze phases d'évolution de la végétation ont été reconnues. Elles se caractérisent par une alternance de phases tempérées humides et de phases fraîches ou froides. Ces phases sont marquées par le développement successif de forêts d'arbres thermophiles (feuillus indigènes ou exotiques) et de forêts de conifères accompagnées d'herbacées.

Les trois carottages réalisés par le Laboratoire de Géologie du Quaternaire de Marseille en 1989 ont recoupé $24 \mathrm{~m}$ de sédiments (Roger et al., 2000). Ils ont permis de reconnaître un téphra à $20,75 \mathrm{~m}$ de profondeur qui a été daté à $2,10 \pm 0,01 \mathrm{Ma}$ par ${ }^{40} \mathrm{Ar} /{ }^{39} \mathrm{Ar}$. La transition paléomagnétique normal (Réunion) / inverse (Matuyama) repérée dans cette séquence a été située vers 2,09 Ma. La séquence pollinique pourrait s'étendre ainsi du stade 85 au stade 76. Sur ces bases une attribution globale de la séquence lacustre au Tiglien est envisageable.

Les formations fossilifères, composées de formations de versant et de hauts niveaux lacustres se rencontrent sur le versant à l'ouest du hameau (fig. 3). Connues depuis la fin du XIX ${ }^{\mathrm{e}}$ siècle (Boule, 1892), elles ont été exploitées au début du $\mathrm{Xx}^{\mathrm{e}}$ siècle (Depéret \& Mayet, 1912; Stehlin, 1923). Les fouilles effectuées entre 2001 et 2006 ont permis de reconnaître leur contexte sédimentaire et ont livré de nouveaux fossiles.

\section{2 - DONNÉES PALÉONTOLOGIQUES}

Les études paléontologiques récentes ont été réalisées par A. Argant, E. Crégut-Bonnoure, E. Delson, V. Eisenmann, M. Faure, J. Gaudant, C. Guérin, M. Hugueney, L. Maul, B. Menouret, C. Mourer-Chauviré et A. Valli.

$\mathrm{Au}$ total quarante espèces de mammifères, seize d'oiseaux et deux de poissons ont été découvertes à Senèze. En ce qui concerne les mammifères, il y a six rongeurs, deux primates, un lagomorphe, dix carnivores, quinze artiodactyles, un proboscidien, cinq périssodactyles.

Rodentia Arvicolidae: Mimomys pusillus (Méhély, 1914); Mimomys pitymyoides Forsyth Major, 1902; Mimomys pliocaenicus Forsyth Major, 1902; Mimomys newtoni Forsyth Major, 1902.

Rodentia Sciuridae: aff. Eutamias sp.

Rodentia Hystricidae: Hystrix refossa Gervais, 1852.

Primates Cercopithecidae: Paradolichopithecus arvernensis (Depéret, 1929); Macaca sylvana cf. florentina (Cocchi, 1872).

Lagomorpha Leporidae: Oryctolagus cf. lacosti (Pomel, 1853).

Carnivora Canidae: Nyctereutes megamastoides megamastoides (Pomel, 1842); Vulpes alopecoides Forsyth Major, 1877; Canis arnensis Del Campana, 1913 (=? Canis senezensis Martin, 1973); Canis sp. ? cf. etruscus Forsyth Major, 1877.

Carnivora Ursidae: Ursus etruscus Cuvier, 1823.

Carnivora Hyaenidae: Pachycrocuta perrieri (Croizet \& Jobert, 1828); Chasmaportethes lunensis (Del Campana, 1914).

Carnivora Felidae: Acinonyx pardinensis pardinensis (Croizet \& Jobert, 1828); Homotherium crenatidens (Fabrini, 1890); Megantereon cultridens (Cuvier, 1824).

Artiodactyla Suidae: Sus strozzii Meneghini, F. Major, 1881 
Artiodactyla Cervidae: Croizetoceros ramosus minor Heintz, 1970; Metacervoceros rhenanus philisi Schaub, 1941; Eucladoceros ctenoides senezensis Depéret \& Mayet, 1910; Libralces gallicus Azzaroli, 1952.

Artiodactyla Bovidae: Gazellospira torticornis (Aymard, 1854); Procamptoceras brivatense Schaub, 1923; Megalovis latifrons Schaub, 1923; Gallogoral meneghinii (Rütimeyer, 1878);

Hemitragus aff. orientalis Spassov \& Crégut-Bonnoure, 1999; Pliotragus ardeus (Depéret, 1884); Ovis sp.; Caprinae indet.; Leptobos (Leptobos) furtivus Duvernois, 1989; Leptobos (Smertiobos) etruscus (Falconer, 1859); Eobison sp.; Bovidae indet.

Proboscidea Elephantidae: Mammuthus meridionalis meridionalis (Nesti, 1825)

Perissodactyla Equidae: Allohippus senezensis (Prat, 1964); Très grand Allohippus, ? Equus bressanus Viret, 1954; ? Allohippus vireti (Prat, 1964); Très petit Allohippus, ? Equus cf. stehlini Azzaroli, 1965.

Perissodactyla Rhinocerotidae: Dicerorhinus etruscus etruscus (Falconer, 1859).

Les espèces de mammifères dominantes sont Eucladoceros ctenoides, Allohippus senezensis, Dicerorhinus etruscus, suivies de Metacervoceros rhenanus et Gallogoral meneghinii.
Pour des raisons taphonomiques (absence de possibilité de nidation pour les oiseaux rapaces, pentes trop fortes et glissements fréquents sur les berges du lac, sédiment trop grossier), le site montre un net déficit en micromammifères: les rongeurs sont très rares, les Insectivores et les Cheiroptères sont totalement absents.

La communauté mammalienne de Senèze présente un mélange de taxons typiques d'un environnement steppique (les chevaux, les Bovidés, le guépard et la hyène chasseresse), d'espèces forestières (les Cervidés, le sanglier, l'ours) et d'espèces ubiquistes. Un tel mélange traduit un paysage en mosaïque évoquant une savane boisée sous un climat relativement humide et sans doute pas particulièrement froid.

$\mathrm{Du}$ point de vue biostratigraphique, le tableau 1 indique l'extension temporelle des principaux mammifères recueillis dans le site. Il montre que Senèze doit être placé dans la standardzone MNQ 18 (Guérin, 2007).

Par ailleurs la communauté des mammifères montre:

- quatre associations caractéristiques: Gallogoral + Metacervoceros rhenanus philisi; Acinonyx + Megalovis latifrons; Pliotragus + Canis senezensis; Libralces gallicus + Sus strozzii;

- la présence de cinq stades évolutifs typiques dans autant de lignées mammaliennes: Allohippus senezensis, Metacervoceros rhenanus philisi, Eucladoceros

\begin{tabular}{|c|c|c|c|c|c|}
\hline Taxon & MNQ 16 & MNQ 17 & MNQ 18 & MNQ 19 & MNQ 20 \\
\hline Paradolichopithecus arvernensis & $\mathbf{X}$ & $\mathbf{X}$ & $\mathbf{X}$ & & \\
\hline Macaca sylvana cf. florentina & $\mathbf{x}$ & $\mathbf{x}$ & $\mathbf{x}$ & $\mathbf{x}$ & \\
\hline Mammuthus meridionalis meridionalis & & $\mathbf{x}$ & $\mathbf{x}$ & & \\
\hline Allohippus senezensis & & & $\mathbf{X}$ & & \\
\hline Très grand Allohippus, ? Allohippus bressan & $\mathbf{X}$ & $\mathbf{X}$ & $\mathbf{x}$ & $\mathbf{x}$ & $\mathbf{X}$ \\
\hline ? Allohippus vireti & & $\mathbf{x}$ & $\mathbf{x}$ & & \\
\hline Très petit Allohippus, ? Allohippus cf. stehlini & & & $\mathbf{x}$ & $\mathbf{x}$ & $\mathbf{x}$ \\
\hline Dicerorhinus etruscus etruscus & $\mathbf{x}$ & $\mathbf{x}$ & $\mathbf{x}$ & $\mathbf{x}$ & \\
\hline Sus strozzii & $\mathbf{X}$ & $\mathbf{x}$ & $\mathbf{x}$ & $\mathbf{x}$ & $\mathbf{x}$ \\
\hline Croizetoceros ramosus minor & & & $\mathbf{x}$ & & \\
\hline Metacervoceros rhenanus philisi & & & $\mathbf{x}$ & & \\
\hline Eucladoceros ctenoides senezensis & & & $\mathbf{x}$ & $x$ & $x$ \\
\hline Libralces (=Alces ?) gallicus & & & $\mathbf{x}$ & $\mathbf{x}$ & $\mathbf{x}$ \\
\hline Gazellospira torticornis & $\mathbf{X}$ & $\mathbf{x}$ & $\mathbf{x}$ & $\mathbf{x}$ & $\mathbf{x}$ \\
\hline Procamptoceras brivatense & & $\mathbf{x}$ & $\mathbf{x}$ & $\mathbf{x}$ & \\
\hline Megalovis latifrons & & $\mathbf{x}$ & $\mathbf{x}$ & & \\
\hline Gallogoral meneghinii & & $\mathbf{x}$ & $\mathbf{x}$ & & \\
\hline Hemitragus sp. & & $\mathbf{x}$ & $\mathbf{x}$ & & \\
\hline Leptobos furtivus & & & $\mathbf{x}$ & $\mathbf{x}$ & $\mathbf{x}$ \\
\hline Leptobos etruscus & & & $\mathbf{x}$ & $\mathbf{x}$ & $\mathbf{X}$ \\
\hline Pliotragus ardeus & $\mathbf{X}$ & $\mathbf{X}$ & $\mathbf{x}$ & & \\
\hline Ovis sp. & & & $\mathbf{x}$ & $\mathbf{x}$ & $\mathbf{x}$ \\
\hline Nyctereutes megamastoides & $\mathbf{x}$ & $\mathbf{x}$ & $\mathbf{x}$ & & \\
\hline Vulpes alopecoides & $\mathbf{x}$ & $\mathbf{x}$ & $\mathbf{x}$ & $\mathbf{x}$ & $\mathbf{x}$ \\
\hline Canis arnensis (= senezensis ?) & & & $\mathbf{x}$ & $\mathbf{x}$ & $\mathbf{x}$ \\
\hline Canis sp. cf. etruscus & & & $?$ & $\mathbf{x}$ & $\mathbf{x}$ \\
\hline Ursus etruscus & $\mathbf{x}$ & $\mathbf{x}$ & $\mathbf{x}$ & $?$ & \\
\hline Pachycrocuta perrieri & $\mathbf{x}$ & $\mathbf{x}$ & $\mathbf{x}$ & $\mathbf{x}$ & $\mathbf{X}$ \\
\hline Chasmaporthetes lunensis & $\mathbf{X}$ & $\mathbf{x}$ & $\mathbf{x}$ & & \\
\hline Acinonyx pardinensis & $\mathbf{x}$ & $\mathbf{x}$ & $\mathbf{x}$ & $\mathbf{x}$ & $\mathbf{x}$ \\
\hline Puma pardoides (Viretailurus schaubi) & $\mathbf{x}$ & $\mathbf{x}$ & $\mathbf{x}$ & $\mathbf{x}$ & $\mathbf{x}$ \\
\hline Homotherium crenatidens & $\mathbf{x}$ & $\mathbf{x}$ & $\mathbf{x}$ & $\mathbf{x}$ & $\mathbf{x}$ \\
\hline Megantereon cultridens & $\mathbf{x}$ & $\mathbf{x}$ & $\mathbf{x}$ & $\mathbf{x}$ & $\mathbf{x}$ \\
\hline Mimomys pusillus & & & $\mathbf{x}$ & $\mathbf{x}$ & $\mathbf{x}$ \\
\hline Mimomys pitymyoides & & $\mathbf{x}$ & $\mathbf{x}$ & & \\
\hline Mimomys pliocaenicus & $\mathbf{X}$ & $\mathbf{x}$ & $\mathbf{x}$ & & \\
\hline Mimomys newtoni & & $\mathbf{x}$ & $\mathbf{x}$ & & \\
\hline Hystrix refossa & $\mathbf{x}$ & $x$ & $\mathbf{x}$ & $\mathbf{x}$ & $\mathbf{x}$ \\
\hline
\end{tabular}

Tab. 1 : Extension temporelle des principaux taxons de mammifères recueillis à Senèze.

MNQ 16: Villafranchien inférieur; MNQ 17: Villafranchien moyen; MNQ 18: Villafranchien supérieur; MNQ 19: Villafranchien terminal; MNQ 20: Pléistocène moyen ancien.

Tab. 1: Temporal extension of the main Mammalian taxa found in Senèze. MNQ 16: Early Villafranchian; MNQ 17: Middle Villafranchian; MNQ 18: Late Villafranchian; MNQ 19: Final Villafranchian; MNQ 20: Early Middle Pleistocene. 
ctenoides senezensis, Croizetoceros ramosus minor, et Leptobos furtivus;

- la première apparition connue de huit espèces: Mimomys pliocenicus; Canis senezensis; Libralces gallicus; Leptobos furtivus; Leptobos etruscus; Procamptoceras brivatense; Megalovis latifrons.

Ce sont là trois caractéristiques participant à la définition de la standardzone MNQ 18, qui correspond au Villafranchien supérieur.

D'après l'ensemble des données fauniques les âges proposés par la biochronologie seraient plus jeunes (de l'ordre de 1,8 à 1,5 Ma) que ceux obtenus par la méthode ${ }^{40} \mathrm{Ar} /{ }^{39} \mathrm{Ar}$ sur les téphras.

\section{3 - STRATIGRAPHIE ET DYNAMIQUE DE DÉPÔT}

\subsection{1 - Stratigraphie}

Les dépôts fossilifères ne sont pas visibles, excepté au niveau d'anciennes coupes. Lors des fouilles de 2001-2006, certaines ont été ravivées, comme la coupe A. L'essentiel des observations géologiques ont pu être menées grâce à la réalisation de tranchées et de décapages horizontaux, à l'ouest et au sud-est du village de Senèze (fig. 4). Ces travaux ont mis au jour des faciès de versant localement fossilifères dans lesquels s'intercalent progressivement des niveaux lacustres.

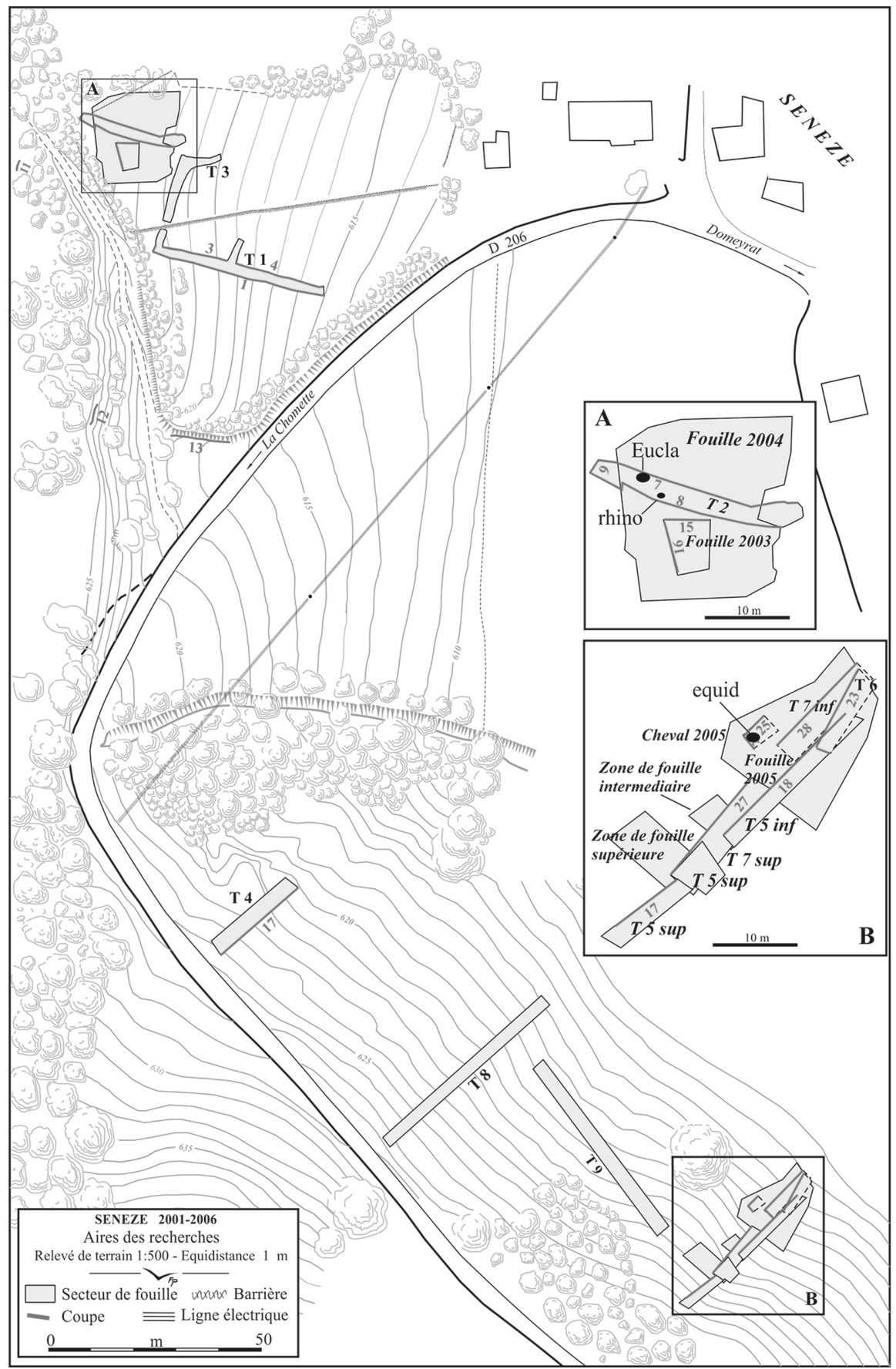

Fig. 4 : Localisation des travaux 2001-2006 (relevés F. Parenti).

7/ Coupe nord de la tranchée 2 (fig. 5);13/ Coupe A (fig. 6); 17-18/ Coupes nord de la tranchée 5 (fig. 7).

Fig. 4: Location of 2001-2006 excavation sectors (surveys by F. Parenti). 7/ North stratigraphical section of trench 2 (fig. 5); 13/ Section A (fig. 6); 17-18/ North stratigraphical sections of trench 5 (fig. 7). 


\subsubsection{1 - Les dépôts dans le secteur ouest}

Trois tranchées y ont été réalisées. Elles ont mis au jour des formations situées entre $626,50 \mathrm{~m}$ et $614 \mathrm{~m}$ d'altitude, plongeant en direction du centre du maar, avec une pente moyenne de 15 à $20^{\circ}$. La tranchée 1 (T1) est la plus longue $(40 \mathrm{~m})$ et s'étend entre $622 \mathrm{~m}$ et $614 \mathrm{~m}$. La tranchée 2 (T2), d'une longueur de $25 \mathrm{~m}$, recoupe les dépôts les plus élevés et descend jusqu'à $620 \mathrm{~m}$ (fig. 5). La tranchée 3 (T3) a été ouverte perpendiculairement aux précédentes sur $15 \mathrm{~m}$ de longueur. Enfin, deux décapages (fouilles 2003 et 2004, fig. 4A) ont été fouillés de part et d'autre de $\mathrm{T} 2$.

Au sud de ces tranchées, la coupe A a été ravivée sur $11,50 \mathrm{~m}$ de longueur et montre des dépôts situés entre 619,30 et $617 \mathrm{~m}$ d'altitude (fig. 6). Au nord, la coupe D (non figurée sur la fig. 4), nettoyée sur une longueur d'environ $8 \mathrm{~m}$ et une hauteur de $6 \mathrm{~m}$, permet d'observer des sédiments entre $628,50 \mathrm{~m}$ et $624 \mathrm{~m}$ d'altitude.

Les unités stratigraphiques, ainsi mises au jour, montrent de nombreuses variations latérales et verticales dues à des changements de faciès et à des déformations cassantes ou souples. On peut les regrouper en 6 ensembles sédimentaires, soit de bas en haut:

- ensemble 1' (T2a à T2g - ensemble inférieur de la coupe A): essentiellement formé de formations de versant, il débute par un microconglomérat (T2a) reprenant des éléments expulsés par le maar et des scories issues du petit cône sommital, accumulés sous forme de dépôt massif en bordure du lac. Sa mise en place a été favorisée par la pente raide du versant et peut-être par l'absence de végétation à cette époque. Cette première unité est recouverte par des niveaux limoneux (T2b, $\mathrm{T} 2 \mathrm{c}$ ), puis plus grossiers (T2d à T2g). T2b, finement laminé, épais au maximum de $20 \mathrm{~cm}$, matérialise un haut niveau lacustre;

- ensemble 2' (T2h - ensemble moyen de la coupe A): il est formé principalement de niveaux limoneux lacustres renfermant plusieurs lits de sable, étirés et boudinés en lentilles, correspondant à des retombées volcaniques. Des apports de versant de granulométrie plutôt fine (graviers gneissiques, petites scories, colluvion) s'interstratifient parfois. L'ensemble 2' a livré un squelette entier de rhinocéros dans la tranchée 2 ainsi que des restes de poissons dans la fouille 2003;

- ensemble 3' (T2i - base de l'ensemble supérieur de la coupe A): ce sont des dépôts de versant avec des microconglomérats plus ou moins grossiers, à matériel gneissique et volcanique, et des limons graveleux, entrecoupés de niveaux limoneux. A l'extrémité de la tranchée 1, ils remanient des niveaux lacustres;

- ensemble 4' : visible seulement dans la tranchée 1, il s'agit d'une colluvion limoneuse s'épaississant vers l'aval, recouvrant et remaniant des limons lités, d'origine lacustre;

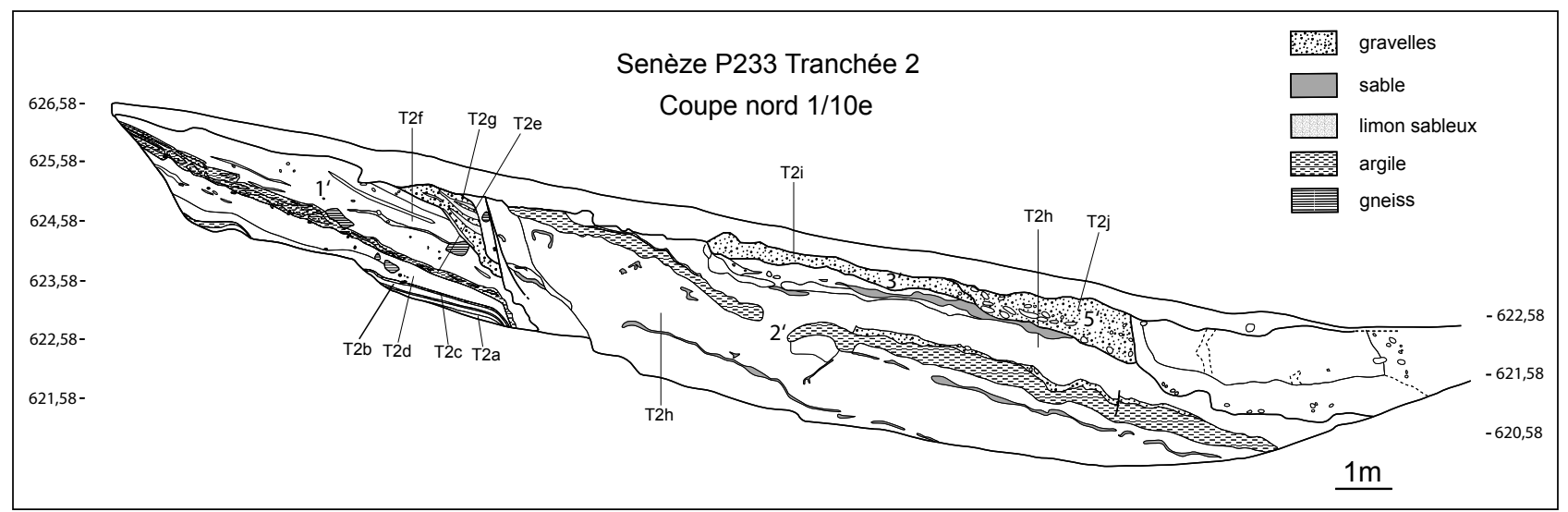

Fig. 5 : Tranchée 2 : coupe stratigraphique nord.

Fig. 5: Trench 2: north stratigraphical section.

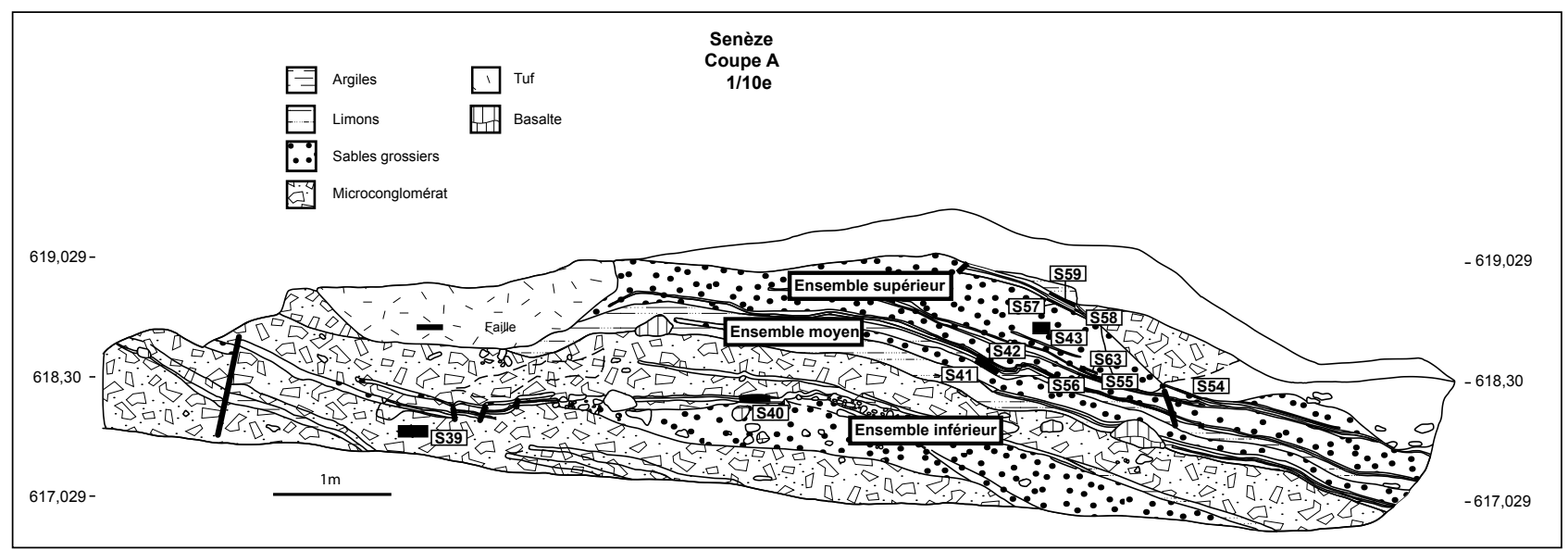

Fig. 6: Coupe A.

Fig. 6: Section A. 
- ensemble 5' (T2 j - sommet de l'ensemble supérieur de la coupe A): il correspond à des apports de versant, très grossiers (de type convoi de blocs) ravinant les ensembles précédents;

- ensemble 6' : il s'agit d'une colluvion fine visible seulement dans la partie aval de la tranchée 1 .

\subsubsection{2 - Les dépôts dans le secteur sud-est}

Six tranchées ont été réalisées dans les dépôts du secteur sud-est.

La tranchée 4 (fig. 4), d'une vingtaine de mètres de longueur, a mis au jour, entre $623,80 \mathrm{~m}$ et $619,80 \mathrm{~m}$ d'altitude, des colluvions remaniant des éléments issus essentiellement de l'altération du socle et comblant un vallon fossile.

Les tranchées 8 et 9 , montrent uniquement des produits phréatomagmatiques plus ou moins accrétionnés, recouverts de dépôts de versant, situés entre $629 \mathrm{~m}$ et $616 \mathrm{~m}$ d'altitude.

La tranchée 5, d'environ $25 \mathrm{~m}$ de longueur, a été creusée en deux parties (T5-sup et T5-inf) entre les cotes 624,70 et $613,40 \mathrm{~m}$. Quatre grands ensembles, présentant une pente moyenne de l'ordre de $20^{\circ}$, affectés de cassures et de figures de glissement, peuvent être distingués, de bas en haut (fig. 7):
- ensemble 1 (unités 1.1 à 1.4): il correspond à un conglomérat grossier, hétérométrique. Sa limite supérieure est irrégulière, de type érosif. Les éléments s'organisent en lits de granulométrie variable: sables grossiers, graviers essentiellement basaltiques, cailloux et petits blocs gneissiques surtout, parfois basaltiques. Il s'agit typiquement d'une formation de versant, remaniant les éléments du socle altéré (arène, blocs émoussés) et les constituants de l'anneau pyroclastique. La mise en place des matériaux s'est faite par unités successives progradant vers l'aval. La présence d'énormes blocs anguleux dans la partie aval de la tranchée suggère une arrivée par coulée de débris;

- ensemble 2 (unités 2.1 à 2.6) : il se caractérise par l'alternance de niveaux limoneux et graveleux dans T5-sup passant à des niveaux plus fins en T5-inf. Un litage, de plusieurs centimètres à quelques millimètres, s'exprime par des différences granulométriques (granules essentiellement basaltiques, millimétriques à infra-millimétriques, sables grossiers à fins, limons). L'ensemble 2 correspond à une formation de versant dont la granulométrie plus fine que celle de l'ensemble 1 , traduit probablement un changement des conditions environnementales (climat moins froid, développement de la végétation);

- ensemble 3: il s'agit d'un conglomérat hétérométrique à support matriciel. Les blocs visibles en T5-sup ont des dimensions importantes (jusqu'à 1,80 $\mathrm{m}$ de

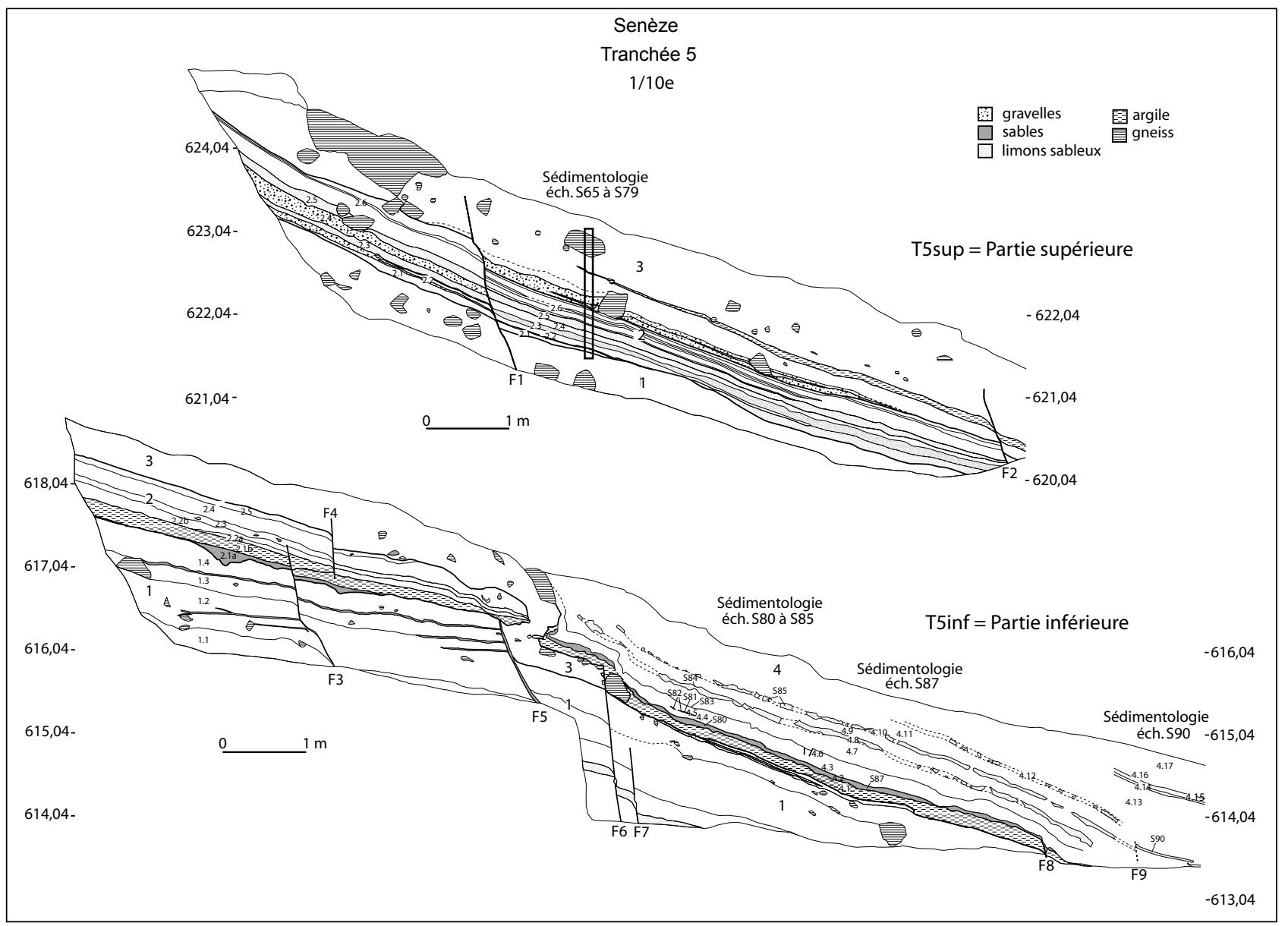

Fig. 7 : Tranchée 5 : coupes nord.

Fig. 7: Trench 5: north stratigraphical sections. 
longueur); ils sont anguleux et proviennent du socle. Ils sont accompagnés par des éléments plus petits (cailloux, graviers) essentiellement basaltiques. La matrice est un sable graveleux, gris à la base en raison de l'abondance des éléments issus du maar, ensuite plus jaune par enrichissement en arène gneissique. On y trouve des grains de quartz, très arrondis, de type fluviatile. L'ensemble 3 correspond à une coulée de débris volumineux arrachés au substratum et à l'anneau pyroclastique;

- ensemble 4 (unités 4.1 à 4.16): visible seulement dans la partie aval de T5-inf, en contact direct avec l'ensemble 1, il est formé de limons plus ou moins grossiers et de sables, regroupés en seize unités, en fonction de la nature des constituants et de leur granulométrie. Les niveaux limoneux, à fines laminations, s'épaississant vers l'aval correspondent à des dépôts lacustres. Ils sont entrecoupés de minces passées détritiques (limons sableux surtout, sables et graviers, petits cailloux parfois) marquant l'arrivée d'apports de versant. Des niveaux de téphras sont présents sous forme de sables ou de limons homométriques.

De nombreuses déformations liées à des mouvements gravitaires ou des tassements mécaniques affectent ces dépôts. Il s'agit de microfailles, de 10 à $20 \mathrm{~cm}$ de rejet, fréquemment soulignées par des infiltrations de sables ou d'argiles, de pli (affectant les ensembles 3 et 4 au milieu de T5-inf), de micro-injections à la partie supérieure de certaines unités $(2.1,4.1)$, d'étirement et de boudinage de certains niveaux $(4.2,4.5)$.

La tranchée 6 a été réalisée à l'aval de la tranchée T5. Sur plus de $6 \mathrm{~m}$ de longueur, elle a mis au jour, entre $613,30 \mathrm{~m}$ et $611,90 \mathrm{~m}$ d'altitude, des dépôts lacustres appartenant à l'ensemble 4, recoupés selon une surface érosive par une accumulation massive de graviers roulés de basalte et de quelques éléments du socle altérés, emballés dans une matrice arénique (ensemble 5).

La tranchée 7, creusée en deux parties entre $619,80 \mathrm{~m}$ et $612,75 \mathrm{~m}$ d'altitude, montre dans sa partie supérieure (T7-sup) des dépôts détritiques de versant et les premiers niveaux lacustres. Ces formations sont à rapprocher de celles décrites dans T5-sup et la moitié supérieure de T5-inf. Plus bas (T7-inf), les dépôts sont essentiellement lacustres. On retrouve les retombées volcaniques décrites dans l'ensemble 4 de T5.

\subsection{2 - Dynamique de mise en place des dépôts fossi- lifères}

Les dépôts de versant, reprenant des éléments du socle et des produits éjectés par le maar, montrent une organisation progradante vers le centre du cratère, selon une pente de 15 à $20^{\circ}$. Ils forment un biseau sédimentaire, caractéristique de la bordure des lacs de maar (Bonifay \& Truze, 1987; Raynal \& Kieffer, 2001; Chapron et al., 2010, 2010-2011). Cette disposition est encore visible dans la morphologie actuelle: alors que les versants du cratère montrent une pente de l'ordre de $35 \%$, on observe une rupture entre 630 et $620 \mathrm{~m}$ d'altitude, marquant la limite supérieure du prisme. Celui-ci semble s'être construit essentiellement dans les parties ouest et sud de la cuvette, les autres côtés étant plus raides.

Les premiers dépôts lacustres apparaissent à la cote de $625 \mathrm{~m}$, au niveau de T2 (fig. 5) où ils s'épaississent rapidement (ensemble $2=\mathrm{T} 2 \mathrm{~h}$ ) et ont été reconnus jusqu'à la cote $620 \mathrm{~m}$, limite inférieure du creusement de cette tranchée. La tranchée T1 montre surtout des dépôts de versant; les niveaux lacustres y apparaissent vers $621 \mathrm{~m}$, avec une épaisseur plus faible qu'en T2 (moins d'un mètre); ils ne se généralisent que vers la cote de $616 \mathrm{~m}$.

Dans le secteur sud-est, les formations de versant sont prépondérantes en T4, T8, T9, T5-sup alors qu'on se trouve à la même hauteur que les niveaux lacustres de la tranchée T2. Le niveau lacustre le plus élevé a été observé en T7-sup à la cote de 619,50 m, c'est-à-dire pratiquement à l'altitude de la base de $\mathrm{T} 2$. La sédimentation lacustre devient continue vers $617,50 \mathrm{~m}$, c'est-àdire à peu près à la même hauteur que dans la tranchée T1. T6 et T7-inf ne montrent que des sédiments lacustres, puisque creusées en dessous de cette cote marquant ainsi la généralisation des niveaux lacustres.

On constate donc d'un secteur à l'autre et même d'une tranchée à l'autre, une grande variabilité dans l'organisation et la nature des dépôts. Plusieurs hypothèses peuvent être proposées pour expliquer ces rapides changements de faciès.

- Le contexte morphologique a visiblement entrainé une évolution de la sédimentation sur le pourtour du cratère. Ainsi, nous avons vu que la construction du biseau littoral s'est effectuée dans les secteurs les moins raides. Ailleurs, les flancs plus escarpés n'ont pas permis une telle organisation. Il existe probablement des abrupts sub-verticaux du socle, comme semblent le démontrer les sondages à la tarière effectués en mars 2005 par le BRGM au pied du versant à proximité de la coupe A. Poussés pour l'un à $22,50 \mathrm{~m}$ et l'autre à $28,50 \mathrm{~m}$ de profondeur, ces investigations n'ont traversé que des formations détritiques fines sans rencontrer le substratum. De nos jours, un tel contexte morphologique peut s'observer sur le côté est du lac d'Issarlès, où le socle affleure largement en bords sub-verticaux. Entre les affleurements rocheux, se sont déposés les dépôts phréatomagmatiques stratifiés, organisés en lentilles à lits progradants vers le lac. Un autre exemple du rôle de la topographie est illustré par la tranchée 4, située à l'aplomb d'un thalweg peu marqué qui a canalisé régulièrement des colluvions.

- Les formations affleurant sur le pourtour du cratère vont jouer également sur la nature des dépôts situés en contrebas. Ceux du secteur ouest ont largement été alimentés par le cône de scories sous forme de pierres, graviers et grains rouges, présents dans toutes les couches. Les tufs phréatomagmatiques ont produit une bonne part du matériel fin mais aussi des blocs, comme celui visible dans la partie ouest de la coupe A. Par contre, côté sud-est, les sédiments ont été en majeure partie nourris par l'érosion du socle gneissique.

- Des remaniements syn- et post-sédimentaires ont entraîné plusieurs types de modifications. Par exemple, on 
observe des figures de charge, d'étirement et de boudinage sur de nombreuses coupes révélant des glissements subaquatiques de certaines unités. Dans certains cas, comme dans les tranchées 2 et 5 , des mouvements, liés peut-être à la dessiccation des sédiments, ont induit des failles de tassement à l'origine d'un abaissement par panneaux des dépôts en direction du centre du maar. D'autres affaissements apparaissent de plus grande amplitude. Ainsi, les dépôts de la zone de la coupe A semblent avoir été affectés par un décollement en masse, révélé par l'absence de déformation des sédiments sous le bloc de tuf et par la présence d'un creux bien marqué entre le pied du versant et le début de l'affleurement. Un glissement a également touché les ensembles supérieurs de la tranchée T5 entraînant leur plissement. Bout (1970) évoque des bouleversements dans les sédiments de la partie supérieure du remplissage lacustre pour expliquer la triple récurrence d'une même phase chaude dévoilée par les spectres polliniques (Elhaï, 1969). Des tels remaniements gravitaires ont été mis en évidence dans les dépôts du lac d'Issarlès (Coûteaux, 1984) et ceux du lac Pavin (Chapron et al., 2010, 2010-2011). Dans le premier cas, plusieurs hypothèses sont proposées pour expliquer ces effondrements sous-lacustres: rupture d'équilibre de sédiments déposés sur une forte épaisseur sur les replats, secousses sismiques, fluctuations du niveau lacustre. Dans le second cas, ils ont été reliés à des baisses rapides du niveau du lac induites par l'incision de l'exutoire, ce qui pourrait être le cas pour Senèze. De nos jours, le départ du ruisseau drainant la cuvette de Senèze se situe à l'altitude de $570 \mathrm{~m}$, soit à plus de $55 \mathrm{~m}$ en contrebas des dépôts fossilifères. Il est possible que l'incision de l'exutoire ait débuté dès le début de leur formation, en relation peut-être avec l'évolution, il y a environ $2 \mathrm{Ma}$, du cours de la Sénouire dans lequel se jette le ruisseau de Senèze (Grangeon, 1967; Pastre et al., 1997).

- La présence de dépôts lacustres interstratifiés avec des formations de versant indique une mise en place des niveaux fossilifères au niveau de la zone de variations du niveau d'eau du paléo-lac. Cette imbrication peut refléter des changements climatiques. Ainsi, l'arrivée des dépôts de versant traduirait plutôt un couvert végétal réduit sur les pentes du cratère, lié à des conditions périglaciaires favorisant des coulées de solifluxion et des ruissellements lors du dégel du sol. Compte tenu des datations obtenues sur les téphras qui placent l'essentiel des dépôts dans l'intervalle 2,21 et 2,09 Ma, cette péjoration du climat pourrait correspondre au refroidissement bien marqué mis en évidence au sein du Tiglien (Popescu et al., 2010). Les niveaux lacustres marqueraient des remontées du lac en raison de précipitations importantes entraînant un bilan hydrique positif. Ce changement, lié à des fluctuations climatiques plus humides, amorcerait le passage aux conditions plus chaudes de la partie supérieure du Tiglien.

\section{4. - SÉDIMENTOLOGIE DES FORMATIONS FOS- SILIFÈRES}

Les résultats concernent des échantillons prélevés dans les niveaux les moins grossiers des tranchées T1, T2, T5, T6, T7, de la coupe A et de la fouille 2003 (fig. 4).
La granulométrie globale révèle la dominance des fractions inférieures à $50 \mu \mathrm{m}$, associées aux sables auxquels s'ajoutent parfois une faible quantité de graviers.

La granulométrie laser des fractions inférieures à $2 \mathrm{~mm}$ montre la prédominance des sables sur les limons qui sont en proportion très variable (de 10 à $45 \%$ ). Elles sont en grande majorité très bien classées $(\mathrm{So}<2,5)$ avec généralement un meilleur classement du côté des particules grossières. Les argiles $(<2 \mu \mathrm{m})$ sont très peu représentées (moins de 2,5\%).

L'illite est présente partout, associée à la chlorite. Quelques échantillons présentent des traces d'argile gonflante. Cette composition minéralogique est différente de celle des sédiments du remplissage lacustre, dominée par la montmorillonite (Grangeon, 1962).

L'analyse micromorphologique effectuée sur quelques échantillons montre partout la présence de détritique (granules laviques, grains de quartz, micas, feldspaths, grenats, sillimanite, oxydes opaques), même dans les niveaux les plus fins.

Ces résultats sont relativement homogènes d'un échantillon à l'autre. Ils suggèrent que les constituants des sédiments ont une origine commune, à partir de formations peu évoluées, issues de l'érosion des roches formant le pourtour du maar. Les phénomènes d'altération pédologique n'ont pas été décelés dans les échantillons analysés. Les variations de granulométrie enregistrées par les sédiments reflètent l'évolution des conditions environnementales, comme celle du régime des pluies entraînant, selon la compétence des ruissellements, l'entraînement de débris plus ou moins gros sur les versants du cratère.

Différents échantillons sableux ont fait l'objet de prélèvements pour l'étude de leurs minéraux lourds (tab. 2). Ceux-ci précisent leur origine. Les clinopyroxènes bruns et l'olivine qui dominent plusieurs échantillons (ex. SEN 2,3, tranchée 2; SEN 25, tranchée 1; SEN 39 coupe A, fig. 6, tab. 3) sont principalement des minéraux basaltiques. Une partie de l'olivine, l'enstatite et le diopside chromifère qui sont communs dans plusieurs échantillons (tab. 3) sont des minéraux mantelliques issus de nodules de lherzolites. Les minéraux du socle métamorphique sont dominés par des grenats et de la sillimanite, associés avec quelques staurotides et andalousites (tab. 3). Si une petite partie de ces minéraux peut provenir des roches dures environnantes (gneiss du cratère, basanite de la coulée), la plupart proviennent des tufs phréatomagmatiques dominant le cratère où ils ont été pulvérisés par les explosions phréatomagmatiques. Les amphiboles brunes peuvent aussi provenir des tufs de maar où elles sont présentes en mégacristaux ou elles peuvent également provenir de téphras du Mont-Dore remaniés. Quelques concentrations importantes de clinopyroxène brun et d'olivine comme dans l'échantillon SEN 59 (sable, partie supérieure de la coupe A, tab. 3) peuvent probablement dériver des scories basaltiques dominant ce secteur (SEN 88 ). Le clinopyroxène vert (diopside automorphe) et la titanite qui sont présents dans plusieurs échantillons (ex. SEN 3, 23, 25, 41, tab. 3) montrent le remaniement de 


\begin{tabular}{|c|c|c|c|c|}
\hline Echant. & Téphra & Coupe & Couche & Type \\
\hline SEN 1 & TS 1 & Tranchée T2 N & hi2 & Sable fin (téphra) \\
\hline SEN 2 & & Tranchée T2 N & d & Sable graveleux \\
\hline SEN 3 & & Tranchée T2 N & $f$ & Sable graveleux \\
\hline SEN 8 & TS 2 & Tranchée T2 N & $\mathrm{b}$ & Sable fin (téphra) \\
\hline SEN 10 & TS 3 & Tranchée T2 S & Ens. f his & Sable fin (téphra) \\
\hline SEN 23 & & Tranchée T1 W & & Microconglomérat \\
\hline SEN 25 & & Tranchée T1 S & & Sable graveleux \\
\hline SEN 33 & & Tranchée T1 N & Base $\mathrm{T} 1 \mathrm{~g}$ & Silt sableux \\
\hline SEN 39 & & A bungalow W & Partie inf. & Sable graveleux \\
\hline SEN 40 & & A bungalow & Partie moy. & Silt \\
\hline SEN 41 & & A bungalow & Partie moy. & Silt \\
\hline SEN 42 & TS 4 & A bungalow & Partie sup. & Silt argileux (téphra) \\
\hline SEN 43 & & A bungalow & Partie sup. & Sable graveleux \\
\hline SEN 51 & TS 5 & Parcelle 233 W & Locus inf. & Sable fin (téphra) \\
\hline SEN 53 & TS 6 & Parcelle $233 \mathrm{~W}$ & hi & Silt sableux (téphra) \\
\hline SEN 54 & THS 5 & A bungalow & Partie sup. & Silt argileux \\
\hline SEN 55 & THS 4 & A bungalow & Partie sup. & Silt argileux \\
\hline SEN 56 & THS 3 & A bungalow & Partie sup. & Silt argileux \\
\hline SEN 57 & THS 2 & A bungalow & Partie sup. & Silt argileux \\
\hline SEN 58 & THS 1 & A bungalow & Partie sup. & Silt avec grains lave \\
\hline SEN 59 & & A bungalow & Partie sup. & Sable hétérométrique \\
\hline SEN 60 & TS 7 & Parcelle 233 W & Locus inf. & Sable fin (téphra) \\
\hline SEN 62 & TS 8 & Tranchée T4 & Ensemble 1 & Silt (téphra) \\
\hline SEN 63 & & A bungalow & Partie sup. & Sable \\
\hline SEN 80 & TS 9 & Tranchée T5 inf. & Unité 4.2 & Sable fin (téphra) \\
\hline SEN 81 & & Tranchée T5 inf. & Unité 4.3 & Sable fin \\
\hline SEN 84 & & Tranchée T5 inf. & Unité 4.8 & Silt argileux \\
\hline SEN 86 & & Tranchée T5 inf. & & Sable graveleux \\
\hline SEN 87 & TS 9 & Tranchée T5 inf. & Unité 4.2 & Silt sableux (téphra) \\
\hline SEN 88 & & Cône scories W & & Cendre et scories \\
\hline SEN 90 & TS 10 & Tranchée T5 inf & Unité 4.10 & Silt sableux (téphra) \\
\hline SEN 96 & THS 6 & D Philis & Unité 8 & Sable \\
\hline SEN 97 & & D Philis & Unité 8 & Sable \\
\hline SEN 98 & TS 9 & Tranchée T5 inf. & Unité 4.2 & Sable a (téphra) \\
\hline SEN 99 & TS 9 & Tranchée T5 inf. & Unité 4.2 & Sable b (téphra) \\
\hline SEN 100 & TS 9 & Tranchée T5 inf. & Unité 4.2 & Silt c (téphra) \\
\hline SEN 101 & TS 10 & Tranchée T5 inf. & Unité 4.10 & Sable a (téphra) \\
\hline SEN 102 & TS 10 & Tranchée T5 inf. & Unité 4.10 & Silt b (téphra) \\
\hline SEN 103 & TS 10 & Tranchée T5 inf. & Unité 4.10 & Silt c lapilli (téphra) \\
\hline
\end{tabular}

Tab. 2 : Provenance et nature des échantillons de sédiments et de téphras prélevés pour l'étude des minéraux lourds. Tab. 2: Location and types of the samples of sediments and tephras sampled for the heavy mineral study.

\begin{tabular}{|c|c|c|c|c|c|c|c|c|}
\hline Minéral/Echantillon & SEN 2 & SEN 3 & SEN 23 & SEN 25 & SEN 33 & SEN 39 & SEN 40 & SEN 41 \\
\hline Amphiboles brunes & 5,3 & 9,2 & 8,1 & 16,8 & 20,1 & 7,8 & 17,6 & 16,4 \\
\hline Enstatite & 11,7 & 10,4 & 11,9 & 14,5 & 5,5 & 7,8 & 12,6 & 4,9 \\
\hline Diopside chromifère & 4,6 & 7,2 & 6 & 6,2 & 4,8 & 5,4 & 10,1 & 1,6 \\
\hline Clinopyroxène brun & 43,6 & 23,7 & 18,2 & 15,9 & 14,6 & 17,6 & 16,8 & 11,5 \\
\hline Clinopyroxène vert & & 2,8 & 5 & 0,3 & & & & \\
\hline $\mathrm{CPx}$ vert basaltique & 0,2 & & 1,6 & 0,9 & & & & \\
\hline Olivine & 32,1 & 28,1 & 6 & 36,9 & 7,8 & 51,2 & 18,5 & \\
\hline \multicolumn{9}{|l|}{ Zircon } \\
\hline Titanite & & 0,4 & 2,2 & 0,3 & 4,9 & & & 6,6 \\
\hline Apatite & & & 1,9 & & & & & \\
\hline Andalousite & & 0,8 & & & & & & \\
\hline Sillimanite & 2,4 & 9,6 & 6,6 & 6,5 & 37,2 & 2,2 & 18,5 & 21,3 \\
\hline Staurotide & & & & & & 2,4 & & 3,3 \\
\hline Grenat & & 7,6 & 32,6 & 1,8 & 5,2 & 5,6 & 5,9 & 34,4 \\
\hline \multicolumn{9}{|l|}{ Autre } \\
\hline Minéral/Echantillon & SEN 43 & SEN 59 & SEN 63 & SEN 81 & SEN 84 & SEN 86 & SEN 88 & SEN 97 \\
\hline Amphiboles brunes & 13,4 & 5,9 & 13 & 40,9 & 51,7 & 14,2 & & 6,2 \\
\hline Enstatite & 1,1 & 2,8 & 1 & & 5 & 3,9 & & 3,7 \\
\hline Diopside chromifère & 0,8 & 2,7 & 0,7 & & 2,5 & 3 & & 1,8 \\
\hline Clinopyroxène brun & 8,6 & 31,2 & 4,1 & 10 & 29,2 & 4,5 & 66,7 & 32,1 \\
\hline Clinopyroxène vert & 49,7 & 10,4 & 56,5 & 1 & 2,5 & & & \\
\hline $\mathrm{CPx}$ vert basaltique & & & & & & & 5,9 & \\
\hline Olivine & 6,3 & 33,1 & 10,4 & & & 64,2 & 22,5 & 56,2 \\
\hline Zircon & 0,3 & & 0,1 & & & & & \\
\hline Titanite & 12,6 & 3 & 10,4 & 7,2 & & & & \\
\hline Apatite & 3,2 & 0,3 & 2,2 & 0,9 & 1,7 & & & \\
\hline Andalousite & & & & & & 0,6 & & \\
\hline Sillimanite & 1,1 & 5,2 & 0,4 & 24,8 & 6,7 & 6,4 & 1 & \\
\hline \multicolumn{9}{|l|}{ Staurotide } \\
\hline Grenat & 3 & 5,4 & 1,1 & 15,2 & 0,8 & 3,1 & 1 & \\
\hline Autre & & & & & & & 2,9 & \\
\hline
\end{tabular}

Tab. 3 : Pourcentages des minéraux lourds (minéraux volcaniques et du socle) des sédiments du site fossilifère de Senèze. Tab. 3: Heavy mineral percentages (volcanic and basement minerals) of the sediments in the Senèze fossiliferous site. 
téphras du Mont-Dore retombés sur les pourtours ou à l'intérieur du cratère. Ils sont particulièrement fréquents dans la partie supérieure de la coupe A (sable graveleux SEN 43, sable SEN 53, tab. 3) où ils font suite au téphra TS 4 et aux horizons téphriques THS 1-5. Le sable fin SEN 81 (partie inférieure de T5) qui contient des amphiboles brunes, du clinopyroxène brun et de la titanite remanie probablement un téphra du Mont-Dore. Le sable graveleux SEN 86 (partie inférieure de T5) qui est dominé par de l'olivine ( $71,3 \%$ des minéraux volcaniques) remanie probablement directement un tuf phréatomagmatique ou peut aussi représenter un tuf in situ.

Ces compositions minéralogiques témoignent des processus gravitaires ou des processus de ruissellement remaniant principalement les tufs phréatomagmatiques de la partie supérieure du cratère.

\section{4 - LES TÉPHRAS DU GISEMENT FOSSILIFÈRE}

\section{1 - OCCURRENCES RÉGIONALES DES TÉPHRAS DU MONT-DORE}

L'activité du strato-volcan du Mont-Dore durant le Pleistocène est à l'origine de nombreux téphras disséminés sur le Massif central et sa périphérie (Pastre, 1987; Teulade, 1989). Ces téphras sont en particulier connus dans les remplissages lacustres de plusieurs cratères de maars (Teulade, 1989; Roger et al., 1999, 2000; Pastre et al., 2007; Nomade et al., 2010; Degeai et al., 2013). Leur occurrence en place ou faiblement remaniés est connue dans différents sites fossilifères (Debard \& Pastre, 1988, 2008; Pastre et al., 1996; Pastre, 2004a, Nomade et al., 2014a). Ils sont largement remaniés dans les alluvions de la haute vallée de l'Allier (Pastre, 1987). A Senèze, un téphra a été trouvé dans le remplissage lacustre et daté à 2,10 $\pm 0,01 \mathrm{Ma}$ par ${ }^{40} \mathrm{Ar} /{ }^{39} \mathrm{Ar}$ (Roger et al., 2000). La localisation du site à $60 \mathrm{~km}$ au sud-est du strato-volcan constitue une condition favorable à la découverte de téphras dans la séquence fossilifère bordant le rivage de l'ancien paléolac. Les autres téphras identifiés dans le secteur se situent à moins de $100 \mathrm{~km}$ en moyenne du strato-volcan et montrent la multiplicité des émissions. La découverte de dix téphras in situ et de six horizons téphriques faiblement remaniés répond à cette perspective et donne une opportunité exceptionnelle pour caractériser le contexte téphrostratigraphique et dater le site.

\section{2 - LOCALISATION ET FACIÈS DES TÉPHRAS ET DES NIVEAUX TÉPHRIQUES}

Les téphras (TS) et les horizons téphriques (THS) $\mathrm{du}$ gisement fossilifère ont été découverts dans les fouilles paléontologiques (tranchées T2 à T5, parcelle $233 \mathrm{~W}$ ) et dans deux coupes préexistantes (coupe A, fig. 6, dénommée aussi «coupe du bungalow», coupe $\mathrm{D}$ dénommée aussi «coupe du ravin Philis»). Les localisations précises sont récapitulées dans le tableau 2. La texture sableuse ou limono-argileuse des échantillons résulte de l'altération qui a causé une dispa- rition complète du matériel vitreux originel (fraction cendreuse / micro-ponces). Le téphra TS 1 (échantillon SEN 1) est un sable fin jaune interstratifié dans l'argile inférieure de la partie moyenne de la tranchée T2 (lit hi 2). Le téphra TS 2 (SEN 8) constitue un niveau sableux fin homométrique situé à la base de la coupe nord de la tranchée T2 (niveau b). Le téphra TS 3 (SEN 10) est aussi un sable fin gris, épais d'un centimètre. Il a été trouvé dans la partie sud de la tranchée T2 (unité f, niveau hi 8). Le téphra TS 4 (SEN 42) est un silt argileux blanc ressemblant à une cendre altérée. Il a été identifié dans la partie supérieure de la coupe A (coupe du «bungalow»). Les téphras TS 5 (SEN 51), TS 6 (SEN 53) et TS 7 (SEN 60) sont des sables fins fournis par la fouille de la parcelle $233 \mathrm{~W}$. Le téphra TS 8 (échantillon SEN 62) est un silt blanc issu de l'ensemble 1 de la coupe non fossilifère T4. Les téphras TS 9 (échantillons SEN 80, 87 et 98) et TS 10 (SEN $90,95,101,102,103)$ ont été découverts dans la tranchée T5. Ils proviennent des unités 4.2 (TS 9) et 4.10 (TS 10). Le téphra TS 9 présente une texture sableuse. Dans une partie de l'affleurement il peut être divisé en trois lits : a (0-2 cm d'épaisseur, sableux), b (2-4 cm, sableux $)$ c (0-0,5 cm, silt argileux blanc). Le téphra TS 10 constitue un lit sableux (a, 2 à $5 \mathrm{~cm}$ d'épaisseur) qui peut être recouvert par un silt sableux blanc $(b, 0$ à $4 \mathrm{~cm}$ ) et par un lit silteux avec des petits lapilli de basalte (c, 0 à $10 \mathrm{~cm}$ ). Les horizons téphriques THS 1-5 (SEN 54, 55, 56, 57, 58) sont des niveaux argilo-silteux blancs faiblement remaniés (cendre altérée) provenant de la partie supérieure de la coupe A («bungalow»). L'horizon téphrique THS 6 est un sable argileux localisé dans la coupe D du «ravin Philis».

\section{3 - MINÉRALOGIE}

A cause de l'absence de verre, les téphras peuvent seulement être caractérisés par leurs feldspaths et leur contenu en minéraux lourds (ferromagnésiens, oxydes et minéraux accessoires). Les feldspaths et les clinopyroxènes ont été étudiés à la microsonde électronique (Cameca SX 100, 15 kV, 10 à 12 nA, temps de comptage 10 secondes). Les minéraux lourds séparés avec du bromoforme $(\mathrm{d}=2,8)$ dans la fraction granulométrique $50 \mu \mathrm{m}-2 \mathrm{~mm}$ ont été décomptés au microscope (silicates et apatite ; oxydes de $\mathrm{Fe}-\mathrm{Ti}=$ principalement magnétite et titanomagnétite, quelques ilménites et biotite-phlogopite non decomptées).

\subsection{1 - Les minéraux lourds}

Les pourcentages de minéraux lourds sont reportés dans le tableau 4 et illustrés par le diagramme de la figure 8. Les spectres sont soit dominés par des amphiboles brunes (kaersutite, pargasite principalement: Ménard, 1979; Pastre \& Cantagrel, 2001), du clinopyroxène brun (diopside $\mathrm{Wo}_{45,4} \mathrm{En}_{41,9} \mathrm{Fs}_{12,7}$ à $\mathrm{Wo}_{49,8} \mathrm{En}_{38}$ $\mathrm{Fs}_{12,2}, \mathrm{Al}_{2} \mathrm{O}_{3}=4,15-10,08 \%, \mathrm{TiO}_{2}=1,08-3,64 \%$ ), du clinopyroxène vert (diopside $\mathrm{Wo}_{46,7} \mathrm{En}_{31} \mathrm{Fs}_{22,3}$ à $\mathrm{Wo}_{48,7}$ $\mathrm{En}_{26,8} \mathrm{Fs}_{24,5}, \mathrm{Al}_{2} \mathrm{O}_{3}=1,02-2,08 \%, \mathrm{TiO}_{2}=0,24-1,18 \%$ ) ou 


\begin{tabular}{|c|c|c|c|c|c|c|c|c|c|c|c|c|}
\hline Mineral/Echantillon & SEN 01 & SEN 08 & SEN 10 & SEN 42 & SEN 51 & SEN 53 & SEN 54 & SEN 55 & SEN 56 & SEN 57 & SEN 58 & SEN 60 \\
\hline Téphra/Horizon téphrique & TS 1 & TS 2 & TS 3 & TS 4 & TS 5 & TS 6 & THS 5 & THS 4 & THS 3 & THS 2 & THS 1 & TS 7 \\
\hline Amphiboles brunes & 7,9 & 20,1 & 41 & 13,2 & 2,7 & 78,2 & 19,7 & 15,3 & 10,5 & 17,8 & 13,1 & 60,5 \\
\hline Enstatite & & & & & & 0,5 & 1,1 & & 0,4 & 2,5 & 5,4 & \\
\hline Diopside chromifère & & & 0,7 & & & & 0,7 & 0,9 & 0,2 & 1,3 & 2,5 & \\
\hline Clinopyroxène brun & & 13,7 & 28,4 & 3,7 & 1,3 & 7,1 & 4,9 & 8,1 & 2,6 & 9,4 & 14,1 & 21,8 \\
\hline Clinopyroxène vert & 29,3 & 46,6 & 20,2 & 60,1 & 60,3 & 10,4 & 34,9 & 45,5 & 60,1 & 36,8 & 35,4 & 8,1 \\
\hline Olivine & & & 6,7 & & & & 3,6 & 8,8 & 1,6 & 3,8 & 2,9 & 4,8 \\
\hline Zircon & 1,4 & 0,3 & & 0,6 & 1,3 & & 0,7 & 0,5 & 0,4 & 0,5 & 0,2 & \\
\hline Titanite & 41,6 & 16,4 & 2,2 & 18,7 & 25,2 & 3,3 & 11,6 & 13,5 & 17,8 & 10,4 & 10,1 & 4,8 \\
\hline Apatite & 19,8 & 2,7 & 0,7 & 3,7 & 9,1 & 0,5 & 1,6 & 1,2 & 2 & 3,8 & 1,6 & \\
\hline Sillimanite & & & & & & & 1,6 & 0,7 & 1,6 & 7,4 & 6,3 & \\
\hline Staurotide & & & & & & & 0,9 & 0,5 & & & & \\
\hline Grenat & & & & & & & 18,8 & 4,9 & 3 & 6,3 & 8,4 & \\
\hline Mineral/Echantillon & SEN 62 & SEN 80 & SEN 87 & SEN 90 & SEN 96 & SEN 98 & SEN 99 & SEN 100 & SEN 101 & SEN 102 & SEN 103 & \\
\hline Tephra/Horizon téphrique & TS 8 & TS 9 & TS 9 & TS 10 & THS 6 & TS 9 & TS 9 & TS 9 & TS 10 & TS 10 & TS 10 & \\
\hline Ampbiboles brunes & 59,2 & 24,5 & 45,8 & 17,6 & 54,3 & 50,4 & 41,8 & 40,4 & 22,7 & 21 & 5,3 & \\
\hline Enstatite & & & & & & & & & & 1 & 1,9 & \\
\hline Diopside chromifère & & & & & & & & & & 0,5 & 1,1 & \\
\hline Clinopyroxène brun & 9,2 & 47,3 & 8,6 & 8,6 & & 23,8 & 33,6 & 23,1 & 30,9 & 27 & 31,7 & \\
\hline Clinopyroxène vert & & 16,8 & 0,5 & 27,3 & & 5,2 & 8,2 & 9,6 & 32 & 25,5 & 9,5 & \\
\hline Olivine & & & & & & & & & & 5,5 & 46,8 & \\
\hline Zircon & & & 0,8 & 0,6 & & 0,8 & & & & & & \\
\hline Titanite & 31,6 & 11,5 & 43,6 & 41,5 & 45,7 & 19,8 & 16,4 & 26,9 & 13,7 & 19,5 & 3,1 & \\
\hline Apatite & & & 0,8 & 4,5 & & & & & 0,8 & & 0,6 & \\
\hline Sillimanite & & & & & & & & & & & & \\
\hline Staurotide & & & & & & & & & & & & \\
\hline Grenat & & & & & & & & & & & & \\
\hline
\end{tabular}

Tab. 4 : Pourcentages des minéraux lourds des téphras et horizons téphriques du Mont-Dore étudiés.

Tab. 4: Heavy mineral percentages of the studied tephras and tephric horizons from the Mont-Dore.

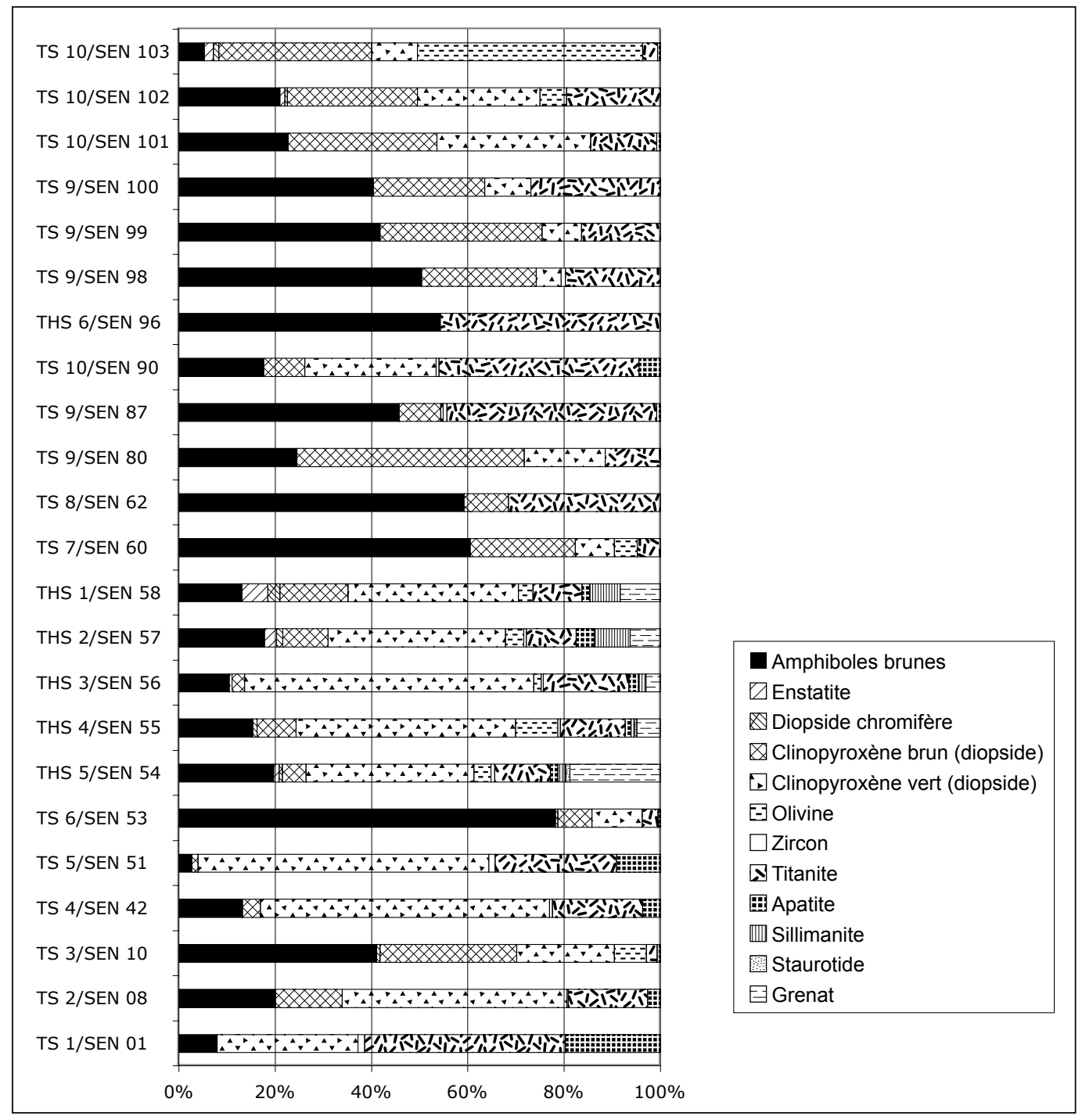

Fig. 8: Spectres de minéraux lourds des téphras et horizons téphriques étudiés.

Fig. 8: Heavy minerals assemblages of the studied tephras and tephric horizons. 
de la titanite. Parmi les minéraux accessoires, les zircons et l'apatite sont présents en faibles pourcentages dans la plupart des échantillons.

Tous ces minéraux sont typiques des pyroclastites du Mont-Dore (Pastre \& Cantagrel, 2001). Le téphra TS 1 (SEN 1) est dominé par la titanite $(41,5 \%)$ suivi par le clinopyroxène vert $(29,3 \%)$ et montre le pourcentage le plus élevé en apatite (19,8\%). Ce spectre caractérise une composition trachytique. Le téphra TS 2 (SEN 8) présente un spectre dominé par le clinopyroxène vert $(46,6 \%)$ caractérisant aussi une composition trachytique (Pastre \& Cantagrel, 2001). TS 3 (SEN 10) est dominé par des amphiboles brunes (41\%), suivies par des clinopyroxènes bruns et verts. Une telle composition pourrait s'accorder avec une composition téphritique (tuf hyaloclastique ou phréatomagmatique) ou latitique. Le téphra TS 4 (SEN 42) contient du clinopyroxène vert $(60,1 \%)$ et de la titanite $(18,7 \%)$; indiquant une composition trachytique (Pastre \& Cantagrel, 2001). Le téphra TS 5 (SEN 51) est dominé par du clinopyroxène vert $(60,3 \%)$, suivi par de la titanite $(25,2 \%)$ et de l'apatite, une composition typique des pyroclastites trachytiques. Le téphra TS 6 (SEN $53)$ est dominé par les amphiboles brunes (78,2\%). Le téphra TS 7 (SEN 60) contient principalement des amphiboles brunes $(60,5 \%)$ et du clinopyroxène brun $(21,8 \%)$. Le téphra TS 8 (SEN 62) comprend des amphiboles brunes $(59,2 \%)$ et de la titanite $(31,6 \%)$. Les échantillons SEN 80, 87, 98, 99 et 100, représentant tous le téphra TS 9 montrent des compositions variables dominées par des amphiboles brunes et du clinopyroxène brun, suivis par de la titanite. Les échantillons SEN 90, 95, 101, 102 et 103, représentant le téphra TS 10 livrent des spectres variables avec des amphiboles brunes, du clinopyroxène brun, du clinopyroxène vert et de la titanite. L'échantillon SEN 103 livre des cristaux d'olivine indiquant une contamination basaltique durant la dernière part de l'éruption comme cela est aussi indiqué par la présence de granules de basalte (micro-lapilli).

Les horizons téphriques THS 1-5 (SEN 54, 55, 56, $57,58)$ sont principalement dominés par du clinopyroxène vert $(34,9-60,1 \%)$ suivis par des amphiboles brunes et de la titanite avec quelques zircons et apatite (tab. 4). Ce sont des téphras faiblement remaniés avec un petit apport de minéraux du socle (sillimanite, grenats et staurotide) et des minéraux basaltiques et mantelliques (clinopyroxènes bruns, olivine, enstatite et diopside chromifère) indiquant leur contamination par du matériel local. L'horizon téphrique THS 6 (SEN 96) contient des amphiboles brunes et de la titanite $(45,7 \%)$. La fréquence de grains de cendre rouge indique probablement sa contamination par les scories dominant le maar.

Parmi les autres minéraux, la biotite/phlogopite est commune dans la plupart des échantillons. Les oxydes de Fe-Ti (principalement de la magnétite et de la titanomagnétite sont fréquents dans la plupart des échantillons (excepté dans SEN 10/TS 3, SEN 53/TS 6, SEN 60/TS 7 , SEN 96/THS 6 où ils sont rares).

\subsection{2 - Les feldspaths}

Les feldspaths sont abondants dans tous les échantillons. Les analyses à la microsonde permettent de mettre en évidence la variabilité des compositions en anorthite $(\mathrm{An})$, albite $(\mathrm{Ab})$ et orthose (Or) dont les pourcentages constituent un moyen pour différencier les téphras. Parmi les 236 analyses réalisées, seulement quelquesunes caractéristiques sont reportées dans le tableau 5. Trois diagrammes ternaires, présentés dans la figure 9 permettent d'identifier les différences caractéristiques de la composition des spectres.

Les feldspaths du téphra TS 1 (SEN 1) sont des feldspaths alcalins (anorthose- sanidine sodique). Leur composition varie entre $\mathrm{Or}_{19,2} \mathrm{Ab}_{69,1} \mathrm{An}_{11,7}$ et $\mathrm{Or}_{45,1} \mathrm{Ab}_{51,9} \mathrm{An}_{3}$. Les feldspaths du téphra TS 2 (SEN 8) sont principalement de la sanidine sodique $\mathrm{Or}_{32,5} \mathrm{Ab}_{61} \mathrm{An}_{6,5}$ à $\mathrm{Or}_{52} \mathrm{Ab}_{46,1} \mathrm{An}_{1,9}$. Le téphra TS 3 (SEN 10) est principalement composé de plagioclases (oligoclase-andésine $\mathrm{Ab}_{49,9} \mathrm{An}_{46,7} \mathrm{Or}_{3,4}$ à $\mathrm{Ab}_{68,1} \mathrm{An}_{22,8} \mathrm{Or}_{9,1}$ ) avec de rares feldspaths alcalins (sanidine sodique $\mathrm{Or}_{40,6} \mathrm{Ab}_{57,1} \mathrm{An}_{2,3}$ ). Le téphra TS 4 (SEN 42) est composé d'un mélange de plagioclases (oligoclaseandésine $\mathrm{Ab}_{51,4} \mathrm{An}_{45,9} \mathrm{Or}_{2,7}$ à $\mathrm{Ab}_{69,6} \mathrm{An}_{19,5} \mathrm{Or}_{10,9}$ ) et de feldspaths alcalins (sanidine sodique $\mathrm{Or}_{49,2} \mathrm{Ab}_{46,8} \mathrm{An}_{4}$ à $\mathrm{Or}_{52,1} \mathrm{Ab}_{44,9} \mathrm{An}_{3}$ ). Le téphra TS 5 (SEN 51) contient principalement de l'anorthose $\mathrm{Or}_{13,2} \mathrm{Ab}_{73,3} \mathrm{An}_{13,5}$ à $\mathrm{Or}_{33,2} \mathrm{Ab}_{61}$ $\mathrm{An}_{5,8}$ et quelques sanidines sodiques (1 grain analysé $\mathrm{Or}_{46,6} \mathrm{Ab}_{50,5} \mathrm{An}_{2,9}$ ). Le téphra TS 6 (SEN 53) contient des feldspaths alcalins (anorthose-sanidine sodique $\mathrm{Or}_{24,8} \mathrm{Ab}_{69,8} \mathrm{An}_{5,4}$ à $\mathrm{Or}_{57,8} \mathrm{Ab}_{40,3} \mathrm{An}_{19}$ ) et des plagioclases (labrador-oligoclase $\mathrm{Ab}_{35,5} \mathrm{An}_{63} \mathrm{Or}_{1,5}$ à $\mathrm{Ab}_{64,7} \mathrm{An}_{29,8} \mathrm{Or}_{5,5}$ ). TS 7 (SEN 60) est principalement composé de plagioclases (oligoclase-andésine $\mathrm{Ab}_{63,8} \mathrm{An}_{30,4} \mathrm{Or}_{5,8}$ à $\mathrm{Ab}_{70,3}$ $\mathrm{An}_{19} \mathrm{Or}_{10,7}$ ) et contient aussi quelques feldspaths alcalins $\mathrm{Or}_{25,4} \mathrm{Ab}_{64,2} \mathrm{An}_{10,4}$ à $\mathrm{Or}_{55,2} \mathrm{Ab}_{41,9} \mathrm{An}_{2,9}$. Le téphra TS 8 (SEN 62) est composé de plagioclases (oligoclase $\mathrm{Ab}_{83,2}$ $\mathrm{An}_{15,3} \mathrm{Or}_{1,5}$ à $\mathrm{Ab}_{77,6} \mathrm{An}_{19,5} \mathrm{Or}_{2,9}$ ) et de feldspaths alcalins (anorthose-sanidine sodique $\mathrm{Or}_{28,5} \mathrm{Ab}_{64,1} \mathrm{An}_{7,4}$ à $\mathrm{Or}_{42,9} \mathrm{Ab}_{55,3} \mathrm{An}_{1,8}$ ). Les feldspaths du téphra TS 9 (SEN 80,87 et 98 ) sont des feldspaths alcalins (anorthose-sanidine sodique $\mathrm{Or}_{23,3} \mathrm{Ab}_{65,6} \mathrm{An}_{11,1}$ à $\left.\mathrm{Or}_{51,5} \mathrm{Ab}_{45,3} \mathrm{An}_{3,2}\right)$. Le téphra TS 10 (SEN 90,95, 101 et 103) est composé de sanidine sodique avec une composition très homogène $\left(\mathrm{Or}_{49,3} \mathrm{Ab}_{46,5} \mathrm{An}_{4,2}\right.$ à $\mathrm{Or}_{55,6} \mathrm{Ab}_{41,8} \mathrm{An}_{2,6}, 52$ analyses$)$. L'horizon téphrique THS 3 (SEN 56) est composé par une sanidine sodique homogène $\left(\mathrm{Or}_{50} \mathrm{Ab}_{46,6} \mathrm{An}_{3,4}\right.$ à $\left.\mathrm{Or}_{56,8} \mathrm{Ab}_{39,6} \mathrm{An}_{3,5}\right)$. Les horizons téphriques THS 1, 2, 4 et 5 n'ont pas été analysés car ils sont probablement issus du même téphra. L'horizon téphrique THS 6 (SEN 96), hétérogène en composition contient de la sanidine sodique $\mathrm{Or}_{38,8} \mathrm{Ab}_{58,1} \mathrm{An}_{3,1}$ à $\mathrm{Or}_{56,8} \mathrm{Ab}_{39,6} \mathrm{An} 3,5$ et de l'anorthose $\mathrm{Or}_{11,4} \mathrm{Ab}_{71,8} \mathrm{An}_{16,8}$ à Or ${ }_{28} \mathrm{Ab}_{66,4} \mathrm{An}_{5,6}$. Toutes ces compositions sont typiques des pyroclastites du MontDore (Pastre \& Cantagrel, 2001 ; Pastre, analyses inédites).

\section{4 - DISCUSSION: IMPLICATIONS TÉPHRO- STRATIGRAPHIQUES}

Les compositions minéralogiques différentes des téphras étudiés impliquent des âges différents pour les 


\begin{tabular}{|c|c|c|c|c|c|c|c|c|c|c|}
\hline Echantillon & SEN 1/1 & SEN $1 / 2$ & SEN $8 / 1$ & SEN 8/2 & SEN 10/1 & SEN 10/2 & SEN 42/1 & SEN 42/2 & SEN 53/1 & SEN 53/2 \\
\hline $\mathrm{Na}_{2} \mathrm{O}$ & 6,037 & 7,275 & 5,14 & 5,875 & 7,787 & 7,332 & 6,04 & 7,984 & 6,9828 & 3,9951 \\
\hline $\mathrm{MgO}$ & 0,003 & 0,008 & 0 & 0 & 0 & 0,001 & 0 & 0 & 0,064 & 0,0262 \\
\hline $\mathrm{Al}_{2} \mathrm{O}_{3}$ & 20,02 & 20,211 & 19,581 & 19,495 & 23,931 & 25,255 & 27,771 & 23,078 & 25,7633 & 30,1362 \\
\hline $\mathrm{SiO}_{2}$ & 64,301 & 65,882 & 64,666 & 64,881 & 62,985 & 60,172 & 56,238 & 61,826 & 58,287 & 51,6043 \\
\hline $\mathrm{K} 2 \mathrm{O}$ & 7,244 & 5,682 & 8,821 & 7,556 & 1,592 & 1,163 & 0,519 & 1,645 & 0,7661 & 0,2472 \\
\hline $\mathrm{CaO}$ & 0,747 & 0,775 & 0,386 & 0,54 & 4,718 & 6,136 & 8,735 & 4,017 & 7,0882 & 12,8851 \\
\hline $\mathrm{TiO}_{2}$ & 0,016 & 0,033 & 0,044 & 0,035 & 0,052 & 0,006 & 0,02 & 0,054 & 0,0363 & 0,0566 \\
\hline $\mathrm{MnO}$ & 0 & 0,012 & 0 & 0 & 0,005 & 0,062 & 0 & 0,051 & 0,047 & 0 \\
\hline $\mathrm{FeO}$ & 0,0196 & 0,212 & 0,264 & 0,236 & 0,315 & 0,317 & 0,379 & 0,384 & 0,4494 & 0,5153 \\
\hline Total oxydes & 98,3876 & 100,09 & 98,902 & 98,618 & 101,385 & 100,444 & 99,702 & 99,039 & 99,4841 & 99,466 \\
\hline $\mathrm{Na}$ & 0,53368 & 0,62952 & 0,45491 & 0,51904 & 0,66277 & 0,63272 & 0,52792 & 0,69577 & 0,61049 & 0,35435 \\
\hline $\mathrm{Mg}$ & 0,0002 & 0,00053 & 0 & 0 & 0 & 0,00007 & 0 & 0 & 0,00043 & 0,0179 \\
\hline $\mathrm{Al}$ & 1,07581 & 1,06311 & 1,05343 & 1,04694 & 1,23812 & 1,32478 & 1,47547 & 1,22251 & 1,36917 & 1,62482 \\
\hline $\mathrm{Si}$ & 2,93176 & 2,94033 & 2,9518 & 2,95636 & 2,76489 & 2,67812 & 2,53519 & 2,77886 & 2,62825 & 2,36072 \\
\hline $\mathrm{K}$ & 0,42132 & 0,32349 & 0,51364 & 0,4392 & 0,08915 & 0,06603 & 0,02985 & 0,09432 & 0,04407 & 0,01443 \\
\hline $\mathrm{Ca}$ & 0,03649 & 0,03706 & 0,01888 & 0,02636 & 0,2219 & 0,29261 & 0,42189 & 0,19345 & 0,34245 & 0,63155 \\
\hline $\mathrm{Ti}$ & 0,00055 & 0,00111 & 0,00151 & 0,0012 & 0,00172 & 0,0002 & 0,00068 & 0,00183 & 0,00123 & 0,00195 \\
\hline $\mathrm{Mn}$ & 0 & 0,00045 & 0 & 0 & 0,00019 & 0,00234 & 0 & 0,00194 & 0,00018 & 0 \\
\hline $\mathrm{Fe}$ & 0,00747 & 0,00791 & 0,01008 & 0,00899 & 0,01156 & 0,0118 & 0,01429 & 0,01443 & 0,01695 & 0,01971 \\
\hline Total cations & 5,00729 & 5,00351 & 5,00425 & 4,99809 & 4,99029 & 5,00866 & 5,00528 & 5,0031 & 5,01321 & 5,00931 \\
\hline An & 3,68 & 3,74 & 1,91 & 2,68 & 22,79 & 29,52 & 43,07 & 19,67 & 34,35 & 63,13 \\
\hline Or & 42,49 & 32,67 & 52,02 & 44,61 & 9,15 & 6,66 & 3,05 & 9,59 & 4,42 & 1,44 \\
\hline$A b$ & 53,83 & 63,58 & 46,07 & 52,72 & 68,06 & 63,82 & 53,89 & 70,74 & 61,23 & 35,42 \\
\hline Echantillon & SEN $80 / 1$ & SEN $80 / 2$ & SEN $87 / 1$ & SEN $87 / 2$ & SEN $87 / 3$ & SEN 90/1 & SEN 90/2 & SEN 95/1 & SEN 95/2 & SEN 95/3 \\
\hline $\mathrm{Na}_{2} \mathrm{O}$ & 6,1983 & 6,0948 & 6,0363 & 6,9069 & 5,7642 & 4,8408 & 5,0235 & 4,981 & 5,0053 & 4,783 \\
\hline $\mathrm{MgO}$ & 0 & 0,003 & 0,0067 & 0,0053 & 0 & 0,0177 & 0 & 0,0042 & 0 & 0,0125 \\
\hline $\mathrm{Al}_{2} \mathrm{O} 3$ & 19,5959 & 19,5245 & 19,669 & 19,5402 & 19,427 & 19,3818 & 19,1315 & 18,9958 & 19,5045 & 19,1325 \\
\hline $\mathrm{SiO}_{2}$ & 65,1738 & 65,6326 & 65,1666 & 65,5854 & 64,9495 & 64,4624 & 64,5304 & 65,2116 & 64,4813 & 64,3684 \\
\hline $\mathrm{K} 2 \mathrm{O}$ & 7,5007 & 7,832 & 7,5526 & 6,4772 & 8,1288 & 9,1882 & 9,0049 & 9,1555 & 8,5957 & 9,3753 \\
\hline $\mathrm{CaO}$ & 0,8521 & 0,5752 & 0,9216 & 0,8785 & 0,7282 & 0,5015 & 0,5885 & 0,5031 & 0,7158 & 0,5058 \\
\hline $\mathrm{TiO}_{2}$ & 0,0285 & 0,0044 & 0,0298 & 0,0363 & 0,026 & 0,0259 & 0 & 0,0408 & 0,017 & 0,0606 \\
\hline $\mathrm{MnO}$ & 0 & 0,0213 & 0,033 & 0 & 0 & 0 & 0 & 0,006 & 0 & 0,0435 \\
\hline $\mathrm{FeO}$ & 0,2162 & 0,2202 & 0,1552 & 0,2071 & 0,2466 & 0,2886 & 0,2994 & 0,1671 & 0,2307 & 0,2386 \\
\hline Total oxydes & 99,5655 & 99,908 & 99,5708 & 99,6369 & 99,2703 & 98,7069 & 98,5782 & 99,0651 & 98,5503 & 98,5202 \\
\hline $\mathrm{Na}$ & 0,54342 & 0,53255 & 0,52905 & 0,60282 & 0,50788 & 0,43008 & 0,44684 & 0,44042 & 0,44424 & 0,42621 \\
\hline $\mathrm{Mg}$ & 0 & 0,0002 & 0,00045 & 0,00036 & 0 & 0,00121 & 0 & 0,00029 & 0 & 0,00086 \\
\hline $\mathrm{Al}$ & 1,04433 & 1,03703 & 1,0479 & 1,03668 & 1,04049 & 1,04673 & 1,03445 & 1,02098 & 1,05228 & 1,03636 \\
\hline $\mathrm{Si}$ & 2,94704 & 2,95783 & 2,94581 & 2,95231 & 2,95155 & 2,95383 & 2,9605 & 2,97388 & 2,95169 & 2,95836 \\
\hline K & 0,43266 & 0,45025 & 0,43552 & 0,37194 & 0,47123 & 0,53708 & 0,527 & 0,53261 & 0,50193 & 0,54966 \\
\hline $\mathrm{Ca}$ & 0,04128 & 0,02777 & 0,04464 & 0,04237 & 0,03546 & 0,02462 & 0,02893 & 0,02458 & 0,03511 & 0,02491 \\
\hline $\mathrm{Ti}$ & 0,00097 & 0,00015 & 0,00101 & 0,00123 & 0,00089 & 0,00089 & 0 & 0,0014 & 0,00059 & 0,00209 \\
\hline$M n$ & 0 & 0,00081 & 0,00126 & 0 & 0 & 0 & 0 & 0,00023 & 0 & 0,00169 \\
\hline $\mathrm{Fe}$ & 0,00818 & 0,0083 & 0,00587 & 0,0078 & 0,00937 & 0,01106 & 0,01149 & 0,00637 & 0,00883 & 0,00917 \\
\hline Total cations & 5,01787 & 5,01491 & 5,01151 & 5,0155 & 5,01687 & 5,00549 & 5,0092 & 5,00075 & 4,99467 & 5,00931 \\
\hline An & 4,06 & 2,75 & 4,42 & 4,17 & 3,49 & 2,48 & 2,88 & 2,46 & 3,58 & 2,49 \\
\hline Or & 42,53 & 44,55 & 43,15 & 36,57 & 46,45 & 54,15 & 52,55 & 53,39 & 51,15 & 54,92 \\
\hline$A b$ & 53,41 & 52,7 & 52,42 & 59,27 & 50,06 & 43,36 & 44,56 & 44,15 & 45,27 & 42,59 \\
\hline
\end{tabular}

Tab. 5: Analyses à la microsonde électronique de feldspaths des téphras caractéristiques des téphras montdoriens de Senèze.

Tab. 5: Electron microprobe analyses of typical feldspars of the Mont-Dore tephras from Senèze.

séquences de dépôts dont ils sont issus. Ces séquences caractérisent plusieurs stades d'évolution du rivage lacustre et des versants du cratère correspondant aux diverses séquences stratigraphiques observées dans les fouilles et tranchées du site paléontologique $(\mathrm{T} 1+\mathrm{T} 2$, parcelle $233 \mathrm{~W}$ et $\mathrm{T} 5$ ) et montrent aussi que les sédiments dans les coupes A et T4 n'ont pas le même âge.

La nature de ces téphras peut être comparée avec la composition des téphras émis durant la phase d'activité du strato-volcan du Mont-Dore vers 2 Ma (Pastre, 1987; Pastre \& Cantagrel, 2001). Si aucune unité pyroclastique connue du Mont-Dore ne peut être corrélée directement avec un téphra de Senèze, plusieurs peuvent être contemporaines.

Dans le secteur de Guéry, dans la partie nord-est du Mont-Dore, la coulée pyroclastique de Guéry possède une composition minéralogique avec de l'anorthose et de la sanidine sodique, des oxydes de Fe-Ti, de la biotite- phlogopite, des amphiboles brunes, du clinopyroxène brun, de la titanite et du zircon (Pastre, 1987; Pastre \& Cantagrel, 2001) qui est proche de plusieurs téphras de Senèze. Elle est associée avec d'autres pyroclastites mineures (coulées et retombées ponceuses) d'âge probablement proche. Elle a été datée à $2,04 \pm 0,03 \mathrm{Ma}$ (Féraud et al., 1990) et 2,08 $\pm 0,01 \mathrm{Ma}$ (Nomade et al., 2014b). Dans la partie nord de ce secteur, les pyroclastites de la bordure ouest du Puy de l'Ouire montrent plusieurs unités dominées par des feldspaths, des oxydes de Fe-Ti et des amphiboles (Pastre, 1987). Plusieurs téphras sont aussi associés avec l'activité sous-saturée (téphrites et trachyphonolites) enregistrée dans ce secteur vers $2 \mathrm{Ma}$ (Nomade et al., 2014b ). Comme pour la plupart des téphras de Senèze, l'occurrence simultanée d'amphiboles brunes, de clinopyroxène brun et de clinopyroxène vert est typique de la majorité des pyroclastites de cette période. Les résultats de cette comparaison s'accordent 


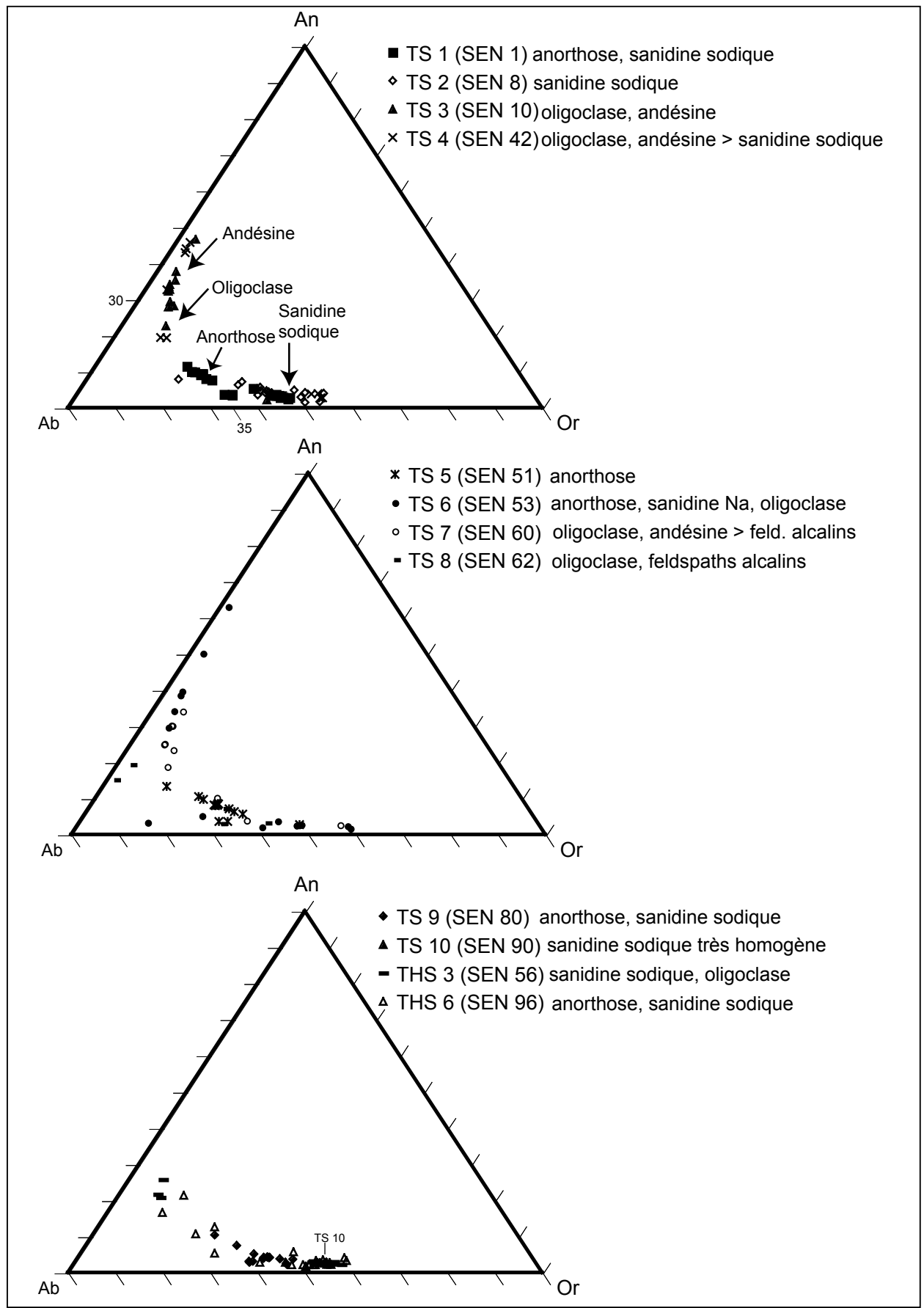

Fig. 9: Diagramme orthose (Or), albite (Ab), anorthite (An) des téphras et horizons téphriques étudiés.

Fig. 9: Orthose (Or), albite (Ab), anorthite (An) diagram of the studied tephras and tephric horizons.

avec les âges ${ }^{40} \mathrm{Ar} /{ }^{39} \mathrm{Ar}$ proches de 2,1 Ma obtenus sur les téphras de Senèze (cf. chapitre 5).

A Blassac, dans la haute vallée de l'Allier, les spectres de minéraux lourds de la séquence fluviatile associée aux produits basaltiques locaux montre l'influence de quatre types de retombées du Mont-Dore: (a) à clinopyroxène vert, (b) à amphiboles brunes et titanite, (c) à clinopyroxène vert et titanite, (d) à amphiboles brunes, clinopyroxène vert et titanite (Pastre, 1987). Ces compositions avec des cortèges dominés par des amphiboles brunes ou du clinopyroxène vert et les âges K-Ar de 2,04 $\pm 0,05$ (Couthures, 1982; Couthures \& Pastre, 1983) et 2,14 \pm $0,06 \mathrm{Ma}$ (Fouris, 1989) obtenus pour la coulée de basalte sus-jacente permettent une comparaison avec les téphras de Senèze.

\section{5 - DATATION ${ }^{40} A R /{ }^{39} A R$ DES TÉPHRAS}

Cinq niveaux de téphras découverts ont été datés par ${ }^{40} \mathrm{Ar} /{ }^{39} \mathrm{Ar}$ sur monocristal de feldspath alcalin: TS 9 (SEN 98) et TS 10 (SEN 101), THS 3 (SEN 56); TS 1 (SEN 1) et TS 2 (SEN 8). Les âges ont été obtenus au laboratoire du LSCE (Gif-Sur-Yvette) suivant le protocole expérimental présenté en détail dans l'article de Nomade et al., (2014a). Les âges sont recalculés relativement au standard ACs-2 à 1,201 Ma (Nomade et al., 2005; Kuiper et al., 2008) et les incertitudes correspondent à un intervalle de confiance à $1 \sigma$ (Renne et al., 2009). Ce choix est motivé par le fait que la charte internationale stratigraphique publiée en 2012 recommande l'utilisation de ces calibrations (Schmitz, 2012). 
L'ensemble des âges obtenus sont compris entre 2,21 $\pm 0,02 \mathrm{Ma}$ à 2,09 $\pm 0,01 \mathrm{Ma}$. Les spectres d'âges et isochrones correspondant à chaque téphra sont présentés figure 10. Les expériences menées sur un échantillon
TS 1, TS 10 montrent des spectres complexes avec un mélange de cristaux anciens (barres grises) et primaires (barres noires) (fig. 10). Néanmoins, en éliminant les cristaux les plus anciens il est possible d'obtenir une popula-
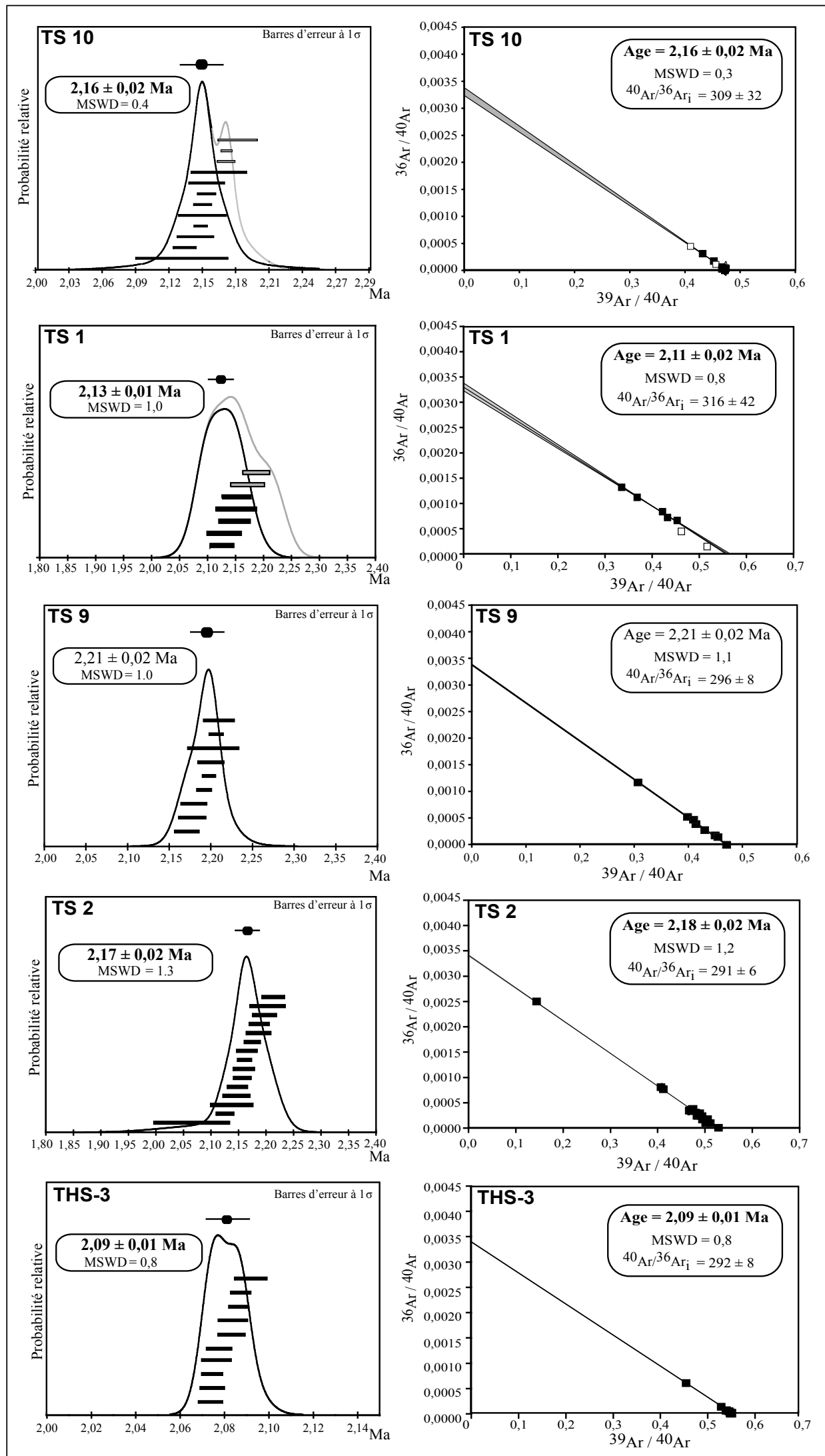

Fig. 10 : Spectres d’âges et isochrones inverses des téphras datés par ${ }^{40} \mathrm{Ar} /{ }^{39} \mathrm{Ar}$ (incertitudes analytiques à $\left.1 \sigma\right)$.

Fig. 10: Age probability distribution spectra, individual age analyses (1 $\sigma$ analytical uncertainties) and corresponding inverse isochron plots for the tephras dated by ${ }^{40} \mathrm{Ar}^{139} \mathrm{Ar}$. 
tion statistiquement homogène permettant de calculer un âge moyen de 2,16 $\pm 0,02 \mathrm{Ma}$ et 2,13 $\pm 0,01 \mathrm{Ma}$, pour TS 10 , et TS 1 respectivement. Les isochrones inverses de ces deux échantillons ont des rapports ${ }^{40} \mathrm{Ar} /{ }^{36} \mathrm{Ar}$ atmosphérique à une incertitude près et suggèrent donc que ces âges ne sont pas affectés par la présence d'excès d'argon. Les diagrammes de probabilités des échantillons TS 9, TS 2, et THS 3 sont simples, dominés par des cristaux primaires. Les isochrones inverses de ces trois échantillons permettent de calculer des rapports ${ }^{40} \mathrm{Ar} /{ }^{36} \mathrm{Ar}$ compatibles à une incertitude près avec le rapport atmosphérique, ce qui suggère que les âges obtenus ne sont pas affectés par de la présence de ${ }^{40} \mathrm{Ar}$ non radiogénique (fig. 10). Les âges moyens pondérés obtenus pour ces trois téphras sont de 2,21 $\pm 0,02 \mathrm{Ma} ; 2,17 \pm 0,02 \mathrm{Ma}$ et $2,09 \pm 0,01 \mathrm{Ma}$ (fig. 10).

\section{6 - CONCLUSION}

Le système volcanique de Senèze est caractérisé par l'association d'une coulée de basanite, des formations scoriacées et des tufs phréatomagmatiques bordant le cratère de maar. Un premier épisode phréatomagmatique caractérisé par des tufs de retombée sub-basanitique précède l'émission de la coulée qui précède elle-même probablement les scories. Après la mise en place de ces formations l'épisode phréatomagmatique principal survient et se traduit par la mise en place des tufs du versant ouest et la formation du cratère de maar.

La faune de vertébrés provient de dépôts de versant et de dépôts lacustres situés sur la paroi du cratère. Les dépôts de versant, remaniant des éléments du socle et des produits éjectés par le maar montrent une organisation progradante vers le centre du cratère. Ils forment un biseau sédimentaire, caractéristique de la bordure des lacs de maars. Les dépôts grossiers attestent d'une érosion importante sur des surfaces dénudées pouvant s'accorder avec des phases de refroidissement plus ou moins marquées du climat. Ces sédiments comprennent dix téphras et six horizons téphriques qui sont typiques de l'activité pyroclastique du Mont-Dore situé une soixantaine de kilomètres au nordouest. Ces téphras altérés, à la fraction vitreuse argilisée, correspondent aux produits émis durant une partie de la phase d'activité pléistocène inférieure du strato-volcan. La différence du contenu minéralogique de ces téphras issus des différents secteurs fouillés montrent le polyphasage du dépôt des sédiments fossilifères.

Les âges ${ }^{40} \mathrm{Ar} /{ }^{39} \mathrm{Ar}$ obtenus sur cinq téphras s'étalent entre 2,21 et 2,09 Ma. Ils représentent ainsi une durée minimale d'environ $100 \mathrm{ka}$ pour la mise en place du site. Il est à signaler que les téphras TS 9 et TS 10 encadrent dans la parcelle T5 P172 un niveau paléontologique et permettent donc avec certitude de dater celui-ci. Les âges obtenus sur les autres téphras des parcelles T2 P233 et P234 sont distincts en âge et en composition minéralogique et suggèrent la présence sur le site de Senèze de différents niveaux paléontologiques durant ces $100 \mathrm{ka}$. Ces niveaux paléontologiques couvrent ainsi probable- ment plusieurs périodes climatiques qui chronologiquement correspondent aux stades isotopiques marins (MIS) 83 à 79. Il est à noter que le MIS 82 est reconnu comme un stade relativement froid (ex. carottage DSDP 380, Popescu et al., 2010).

Ces données montrent l'importance de l'activité pyroclastique du Mont-Dore contemporaine de la mise en place du gisement fossilifère. La richesse de sa faune le confirme comme un site-clé du Pléistocène inférieur. Les datations ${ }^{40} \mathrm{Ar} /{ }^{39} \mathrm{Ar}$ obtenues en font actuellement le gisement le mieux daté pour cette période en Europe occidentale.

\section{RÉFÉRENCES BIBLIOGRAPHIQUES}

ABLIN D., 1991 - Analyse pollinique des dépôts lacustres de Ceyssac, Plio-Pléistocène du Velay (Massif central, France). Cahiers de Micropaléontologie, 6 (1) 21-38.

BONIFAY E. \& TRUZE E., 1987 - Dynamique sédimentaire et évolution des lacs de maars: l'exemple du Velay. Documents $d u$ C.E.R.L.A.T., 1, 29-64.

BOULE M., 1892 - Découverte d'un squelette d'Elephas meridionalis dans les cendres basaltiques du volcan de Senèze (Haute-Loire). Comptes Rendus Hebdomadaires des Séances de l'Académie des Sciences, 115, 624-626.

BOUT P., 1960 - Le Villafranchien du Velay et du bassin hydrographique moyen et supérieur de la Loire. Imprimerie Jeanne d'Arc, Le Puy, $344 \mathrm{p}$.

BOUT P., 1970 - Problème de volcanisme XV: Le maar de Senèze (Haute-Loire). Revue d'Auvergne, 84, 54-68.

BOUT P., 1978 - Le maar de Senèze (Haute-Loire). In P. Bout, Problèmes du volcanisme en Auvergne et Velay. Imprimerie Watel, Brioude, 150-164

BROUSSE R. \& LEFÈVRE C., 1990 - Le volcanisme en France et en Europe limitrophe. Guides géologiques régionaux. Masson, Paris, $262 \mathrm{p}$.

CHAPRON E., ALBÉRIC P., JÉZÉQUEL D., VERSTEEG W., BOURDIER J.-L. \& SITBON J., 2010 - Multidisciplinary characterisation of sedimentary processes in a recent maar lake (Lake Pavin, French Massif Central) and implication for natural hazards. Natural Hazards and Earth System Sciences, 10, 1815-1827.

CHAPRON E., ALBÉRIC P., JÉZÉQUEL D., LEDOUX G. \& MASSAULT M., 2010-2011 - Les archives sédimentaires de l'histoire du lac Pavin. Revue des Sciences Naturelles d'Auvergne, 74-75, $57-65$.

COÛTEAUX M., 1984 - Recherches pollenanalytiques au lac d'Issarlès (Ardèche, France): évolution de la végétation et fluctuations lacustres. Bulletin de la Société Royale de Botanique Belge, 117, 197-217

COUTHURES J., 1982 - Contribution à la chronostratigraphie de formations plio-pléistocène du Massif Central (France). Thèse de Doctorat, Université Paris 6 Pierre et Marie Curie, 2 vol., 180 p.

COUTHURES J. \& PASTRE J.-F., 1983 - Chronostratigraphie du Plio-Pléistocène d'Auvergne et du Velay: nouveaux apports des datations radiométriques et du paléomagnétisme. Bulletin de l'Association Française pour l'Etude du Quaternaire, 20 (1), 9-18.

COUThuRES J., ABLIN D. \& HADJOUIS D., 1991 - Senèze (Haute-Loire) Rapport de fouilles 1991. Direction Régionale des Affaires Culturelles - Auvergne, Clermont-Ferrand, $55 \mathrm{p}$.

DEBARD É. \& PASTRE J.-F., 1988 - Un marqueur chronostratigraphique du Pléistocène moyen à la périphérie du Massif Central: la retombée à clinopyroxène vert du Sancy dans le site acheuléen d'Orgnac III (Bas Vivarais, S-E France). Comptes Rendus de l'Académie des Sciences. Série 2, Mécanique, Physique, Chimie, Sciences de l'Univers, Sciences de la Terre, 306, 1515-1520.

DEBARD É. \& PASTRE J.-F., 2008 - Nouvelles données sur les téphras pléistocènes piégés dans les remplissages karstiques ardéchois (SE France). Quaternaire, 19 (2), 107-116.

DEFIVE E., GAUTHIER A. \& PASTRE J.-F., 2005 - L'évolution plio-quaternaire du bassin du Puy (Massif Central, France) : rythmes morphosédimentaires et volcanisme. Quaternaire, 16 (3), 177-190.

DEGEAI J.-P., PASTRE J.-F, GAUTHIER A., ROBERT V., NOMADE S., BOUT-ROUMAZEILLES V. \& GUILLOU H., 2013 - La séquence lacustre du maar d'Alleret (Massif central, 
France): téphrochronologie et évolution paléoenvironnementale en Europe occidentale au début du Pléistocène moyen. Quaternaire, 24 (4), 443-460.

DELSON E., FAURE M., GUÉRIN C., APRILE L., ARGANT J., BLACKWELL B., DEBARD É., HARCOURT-SMITH W., MARTIN-SUAREZ E., MONGUILLON A., PARENTI F., PASTRE J.-F., SEN S., SKINNER A.R., SWISHER III C.C. \& VALLI A.M.F., 2006 - Franco-American renewed research at the Late Villafranchian locality of Senèze (Haute-Loire, France). Courier - Forschungsinstitut Senckenberg, 256, 275-290.

DEPÉRET C. \& MAYET L., 1912 - Le gisement de mammifères pliocènes de Senèze (Haute-Loire) et sa faune paléomammalogique. In Association française pour l'avancement des Sciences fusionnée avec l'Association scientifique de France - Compte rendu de la $40^{\text {me }}$ session - Dijon - 1911 - Notes et Mémoires. Mémoire hors volume (suppl. vol. 2). Masson, Paris, 261-263.

DEVIS G., 1969 - Le volcanisme du Brivadois. Diplôme d'Etudes Supérieures, Université de Clermont-Ferrand, Clermont-Ferrand, $175 \mathrm{p}$.

DEVIS G., 1970 - Le volcanisme et le gisement fossilifère de Senèze. Revue des Sciences Naturelles d'Auvergne, 36, 25-87.

ELHAÏ H., 1969 - La flore sporo-pollinique du gisement villafranchien de Senèze (Massif central, France). Pollen et Spores, 11 (1), 127-139.

FÉRAUD G., LO BELLO P., HALL C.M., CANTAGREL J.-M., YORK D. \& BERNAT M., 1990 - Direct dating of Plio-Quaternary pumices by ${ }^{40} \mathrm{Ar} /{ }^{39} \mathrm{Ar}$ step-heating and single-grain laser fusion methods: the example of the Monts-Dore massif (Massif Central, France). Journal of Volcanology and Geothermal Research, 40 (1), 39-53.

FOURIS M. 1989 - Les sites villafranchiens du Devès et les basaltes de la vallée de l'Allier: application de la méthode $K-A r$. Thèse de Doctorat, Université Blaise Pascal, Clermont-Ferrand, 206 p.

GRANGEON P., 1962 - Note préliminaire à l'étude géologique du volcan et du gisement fossilifère de Senèze. Compte Rendu Sommaire des Séances de la Société Géologique de France, 5, 149-150.

GRANGEON P., 1967 - Le cours villafranchien de la Sénouire dans le Bassin de Paulhaguet et quelques remarques sur certains phénomènes volcaniques de la région au S-E de Cerzat (Haute-Loire Massif central français). Bulletin de l'Association Française pour l'Etude du Quaternaire, 4 (2), 145-163.

GUÉRIN C., 2007 - Biozonation continentale du Plio-Pléistocène d'Europe et d'Asie occidentale par les mammifères : état de la question et incidence sur les limites Tertiaire/Quaternaire et Plio/Pléistocène. Quaternaire, 18 (1), 23-33.

KUIPER K.F., DEINO A., HILGEN F.J, KRIJGSMAN W., RENNE P.R. \& WIJBRANS J.R, 2008 - Synchronizing rock clocks of Earth History. Science, $\mathbf{3 2 0}$ (5875), 500-504.

LASNIER B., MARCHAND J., BAMBIER A., BATARD F., BONIFAY E., BOUILLER R., BURG J.-P., CORNEN G., DUPONT, FORESTIER F.-H., GAGNIÈRE G., GRENIER E. \& LEYRELOUP A., 1982 - Carte géologique de la France à 1/50 000 $\left(n^{\circ} 766\right)$, Brioude (2634). Notice explicative. Bureau de Recherches Géologiques et Minières, Orléans, $68 \mathrm{p}$

MAURY R.C. \& VARET J., 1980 - Le volcanisme tertiaire et quaternaire en France. In A. Autran \& J. Dercourt (eds.), Evolutions géologiques de la France: texte intégral du Colloque C7, Géologie de la France, du $26^{e}$ Congrès géologique international. Mémoires du BRGM, 107. Editions du BRGM, Orléans, 138-159.

MÉNARD J.-J., 1979 - Contribution à l'étude pétrogénétique des nappes de ponces du massif volcanique du Mont-Dore (Massif Central français). Thèse de Doctorat, Université Paris-Sud, Orsay, $105 \mathrm{p}$.

NEHLIG P., BOIVIN P., DE GOËR A., MERGOIL J., PROUTEAU G., SUSTRAC G. \& THIÉBLEMONT D., 2003 - Les volcans du Massif central. Géologues, numéro spécial Massif Central, 1-41.

NOMADE S., RENNE P.R., VOGEL N., DEINO A.L., SHARP W.D., BECKER T.A., JAOUNI A.R. \& MUNDIL R., 2005 - Alder Creek sanidine (ACs-2): A Quaternary ${ }^{40} \mathrm{Ar} /{ }^{39} \mathrm{Ar}$ dating standard tied to the Cobb Mountain geomagnetic event. Chemical Geology, 218 (3-4), 315-338.

NOMADE S., GAUTHIER A., GUILLOU H. \& PASTRE J.-F., $2010-{ }^{40} \mathrm{Ar} /{ }^{39} \mathrm{Ar}$ temporal framework for the Alleret maar lacustrine sequence (French Massif Central): Volcanological and paleoclimatic implications. Quaternary Geochronology, 5 (1), 20-27.

NOMADE S., PASTRE J.-F., GUILLOU H., FAURE M., GUÉRIN C., DELSON E., DEBARD É., VOINCHET P. \& MESSAGER E., 2014a $-{ }^{40} \mathrm{Ar} /{ }^{39} \mathrm{Ar}$ constraints on some French landmark Late Pliocene to Early Pleistocene large mammalian paleofaunas: Paleoenvironmental and paleoecological implications. Quaternary Geochronology, 21, 2-15.
NOMADE S., PASTRE J.-F,, NEHLIG P., GUILLOU H., SCAO V. \& SCAILLET S., 2014b - Tephrochronology of the Mont-Dore volcanic Massif (Massif Central, France): new ${ }^{40} \mathrm{Ar} /{ }^{39} \mathrm{Ar}$ constraints on the Late Pliocene and Early Pleistocene activity. Bulletin of Volcanology, 76 (3) :798. doi: 10.1007/s0045-014-0798-6.

PASTRE J.-F., 1987 - Les formations plio-quaternaires du bassin de l'Allier et le volcanisme régional (Massif Central, France). Thèse de Doctorat, Université Paris 6 Pierre et Marie Curie, Paris, 2 vol., $733 \mathrm{p}$.

PASTRE J.-F., 2004a - Le cryptotéphra de Saint-Vallier : comparaison avec d'autres retombées pyroclastiques du Mont-Dore issues de gisements mammaliens plio-pléistocènes du Massif Central. Implications chronostratigraphiques. Geobios, 37 (1), 44-57.

PASTRE J.-F., 2004b - The Perrier Plateau: A Plio-Pleistocene long fluvial record in the river Allier basin, Massif Central, France, Quaternaire, 15 (1-2), 87-101.

PASTRE J.-F. \& CANTAGREL J.-M., 2001 - Téphrostratigraphie du Mont-Dore (Massif Central, France). Quaternaire, 12 (4), 249-267.

PASTRE J.-F., BILLARD A., DEBARD É., FAURE M. \& GUÉRIN C., 1996 - Un nouvel horizon téphrique du Mont-Dore repéré dans les loess plio-pléistocènes du gisement fossilifère de Saint-Vallier (Drôme, France). Comptes Rendus de l'Académie des Sciences. Série 2, Sciences de la Terre et des Planètes, 323 (7), 607-614.

PASTRE J.-F., DEFIVE E., GABLIER F. \& LAGEAT Y., 1997 Changements hydrographiques et volcanisme plio-quaternaire dans les bassins de la Loire et de l'Allier (Massif central, France). Géographie Physique et Quaternaire, 51, (3), 295-314.

PASTRE J.-F., GAUTHIER A., NOMADE S., ORTH P., ANDRIEU A., GOUPILLE F., GUILLOU H., KUNESCH S., SCAILLET S. \& RENNE P.R., 2007 - The Alleret maar (Massif Central, France): A new lacustrine sequence of the early Middle Pleistocene in western Europe. Comptes Rendus Geosciences, 339 (16), 987-997.

POPESCU S.M., BILTEKIN D., WINTER H., SUC J.-P., MELINTE-DOBRINESCU M.C., KLOTZ S., RABINEAU M., COMBOURIEU-NEBOUT N. CLAUZON G. \& DEACONU F., 2010 - Pliocene and Lower Pleistocene vegetation and climate changes at the European scale: Long pollen records and climatostratigraphy. Quaternary International, 219 (1-2), 152-167.

PRÉVOT M. \& DALRYMPLE G.B., 1970 - Un bref épisode de polarité géomagnétique normale au cours de l'époque inverse Matuyama. Comptes Rendus Hebdomadaires des Séances de l'Académie des Sciences. Série D, Sciences Naturelles, 271 (3), 2221-2224.

RAYNAL J.-P. \& KIEFFER G., 2002 - De l'éruption à l'objet préhistorique en Velay, France. Les dossiers de l'Archéo-Logis, 2, 31-40.

RENNE P.R., DEINO A.L., HAMES W.E., HEIZLER M.T., HEMMING S.R., HODGES K.V., KOPPERS A.A.P., MARK D.F., MORGAN L.E., PHILLIPS D., SINGER B.S., TURRIN B.D., VILLA I.M., VILLENEUVE M. \& WIJBRANS J.R., 2009 - Data reporting norms for ${ }^{40} \mathrm{Ar} /{ }^{39} \mathrm{Ar}$ geochronology. Quaternary Geochronology, 4 (5), 346-352.

ROGER S., FÉRAUD G., DE BEAULIEU J.-L., THOUVENY N., COULON C., COCHEMÉ J.-J., ANDRIEU V. \& WILLIAMS T, $1999-{ }^{40} \mathrm{Ar} /{ }^{39} \mathrm{Ar}$ dating on tephra of the Velay maars (France): implications for the Late Pleistocene proxy-climatic record. Earth and Planetary Science Letters, 170 (3), 287-299.

ROGER S., COULON C., THOUVENY N., FÉRAUD G., VAN VELSEN A., FAUQUETTE S., COCHEMÉ J.-J., PRÉVOT M. \& VEROSUB K.L., $2000-{ }^{40} \mathrm{Ar} /{ }^{39} \mathrm{Ar}$ dating of a tephra layer in the Pliocene Senèze maar lacustrine sequence (French Massif Central): constraint on the age of the Reunion-Matuyama transition and implications on paleoenvironmental archives. Earth and Planetary Science Letters, 183 (3-4), 431-440.

SCHMITZ M.D., 2012 - Radiogenic isotope geochronology. In F.M. Gradstein, J.G. Ogg \& M.D. Schmitz (eds.), The geological Time Scale 2012. Elsevier, Oxford, Amsterdam \& Waltham, 115-125.

STEHLIN H.G., 1923 - Die oberpliocäne Fauna von Senèze (HauteLoire). Eclogae Geologicae Helvetiae, 18 (2), 268-281.

TEULADE A., 1989 - Téphrologie des formations cendro-ponceuses en milieux lacustres quaternaires: méthode d'étude et applications au Massif Central français (Velay) et aux Carpathes orientales roumaines (dépression de Brasov). Thèse de Doctorat, Université Aix-Marseille 2, Aix-en-Provence, 249 p. 